\title{
Relaciones de parentesco entre los miembros de la sociedad económica matritense en el reinado de Fernando VII (1808-1833)
}

\author{
Elisa Martín-Valdepeñas Yagüe \\ UNED
}

\section{The family relationship among the Madrid Economic Society during the Fernando VII Kingdom (1808-1833)}

\begin{abstract}
RESUMEN
Durante el primer tercio del siglo XIX, la Real Sociedad Económica Matritense de Amigos del País, surgida al amparo de la llustración, sufrió las consecuencias de la inestabilidad política a la que se vio sometida España. Aun así, gracias al esfuerzo de algunos de sus componentes, logró su supervivencia en una coyuntura política, económica y social desfavorable. Por un lado, es necesario dar una visión general de la actividad de la Sociedad Matritense en el reinado de Fernando VII para tratar de entender la labor desarrollada y su importancia en el tránsito del Antiguo Régimen al Liberalismo, y por otro, analizar

el proceso de admisión de socios y su evolución en el periodo considerado. Finalmente, a través del estudio de las vinculaciones de parentesco observadas entre los integrantes, se tratará de conocer el funcionamiento de las relaciones sociales y los vínculos con el poder de las élites madrileñas del primer tercio del siglo XIX.
\end{abstract}

PALABRAS CLAVE: Sociedad Económica Matritense, Fernando VII, Guerra de la Independencia, Nobleza, Burguesia, Sistema de parentesco.

\section{ABSTRACT}

During the first third of the $x \mid x$ century, the Economic Society of Madrid (Real Sociedad Economica Matritense de Amigos del País), underwent the consequences of the political instability in Spain. The Society, founded under the protection of the Enlightenment, managed to survive against an unfavourable political, economical and social environment, thanks to the efforts of some of their members. In one hand, a general vision of the Society during the King Fernando VII reign is necessary for understanding the activities developed and its importance during the transition from the Old Regime to the Liberalism. In the other hand, it should be analysed the member admission procedure and its evolution during the considered period. Finally, by means of lineage relationships identified among the members, the behaviours in social relationships will be approached, as well as the close contacts with the power of the elites in Madrid at the first third of the XIX century.

\section{KEYWORDS:}

Economic Society of Madrid, King Fernando VII, Peninsular War, Noblesse, Bourgeoisie, Parentage. 


\section{LA REAL SOCIEDAD ECONÓMICA MATRITENSE DE AMIGOS DEL PAÍS}

El auge de la llustración en el último cuarto del siglo xvIII permitió un ambiente favorable para el desarrollo económico que se tradujo en la difusión de las ciencias útiles, el adiestramiento en los oficios, revisar y modificar las ordenanzas de los gremios y organizar el comercio. En este contexto surgieron las Sociedades Económicas de Amigos del País. La pionera fue la Real Sociedad Bascongada de Amigos del País fundada en 1763 gracias a las iniciativas del conde de Peñaflorida. Posteriormente, la creación de estas instituciones fue protegida por los poderes públicos, sobre todo a raíz de que Pedro Rodríguez Campomanes en 1774 recomendase su fundación'1. En principio estuvieron formadas por nobles y eclesiásticos, abriéndose paso pronto funcionarios, militares, científicos y personas procedentes del comercio, ya que no existían impedimentos de clase para ser socios. "Se puede afirmar que la parte principal de la minoría selecta española figura entre los "Amigos del País" ${ }^{2}$.

La Sociedad Económica Matritense de Amigos del País fue fundada en 1775 por Vicente Rivas, José Faustino Medina y José Almarza con el objetivo de "conferir y producir memorias para mejorar la industria popular y los oficios, los secretos de las artes, las máquinas para facilitar las maniobras, y auxiliar la enseñanza. Además el objeto de la agricultura y cría de caballos será otra de sus ocupaciones, tratando por menor los ramos subalternos relativos á la labranza, y crianza". La tarea de divulgación también estaba presente ya que «En sus memorias anuales dará al público los discursos que vayan trabajando los Socios"». Su creación fue aprobada con el beneplácito del entonces fiscal del Consejo de Castilla, el citado Campomanes. Se inauguró oficialmente el 16 de septiembre de 1775 en las Casas Consistoriales de Madrid y sus Estatutos fueron sancionados por el Rey, Carlos III, el 9 de noviembre de 1775. La Real Sociedad Económica Matritense fue el prototipo de institución ilustrada, de hecho sus Estatutos sivieron de modelo al resto de Sociedades económicas. En su seno se realizaron importantes informes sobre la situación económica y social de la España del Antiguo Régimen. La preocupación por la agricultura es una constante, destacando las memorias sobre la manera de sembrar, el cultivo del trigo y los abonos ${ }^{4}$.

Otro campo de interés fue la industria y el comercio. La Sociedad Matritense fue la encargada de revisar las ordenanzas de los gremios y los llamados privilegios de patente, que consistian en la concesión de la exclusividad para la fabricación o co-

1 G. ANes Álvarez de CASTRILlón: El Antiguo Régimen: Los Borbones, Historia de España Alfaguara, t. IV, Alianza Editorial, Madrid, 1975, pág. 399. El conde Campomanes había recomendado a las autoridades locales la creación de Sociedades económicas en su Circular del 18 de noviembre de 1774.

2 J. Sarrallh: La España ilustrada en la segunda mitad del siglo xVIII, Fondo de Cultura Económica, Madrid, 1957, p. 257.

3 Real Cedula de S. M. y señores del consejo en que se aprueban los estatutos de la Sociedad económica de amigos del Pais, con lo demás que se expresa, á fin de promover la agricultura, industria y oficios, Imp. de Pedro Marin, Madrid, 1775, arts. 2, 3 y 4.

4 J. SARRAILH: ob. cit., p. 262. 
mercialización de un invento durante un número determinado de años. Durante estos primeros años se comprobó la utilidad de gran número de máquinas preindustriales, predominando los ingenios textiles y sistemas aplicados a los molinos ${ }^{5}$. También se instaló el Gabinete de Máquinas, colección de toda una serie de aparatos de utilidad para la fabricación de manufacturas o en la transformación de productos agrícolas. Asimismo, la beneficencia y educación fueron áreas a las que la Sociedad Matritense prestó siempre atención, no hay que olvidar que el lema de la corporación era «Socorre enseñando". Hubo varias iniciativas en este primer campo como el concurso de memorias de 1781, Sobre el ejercicio discreto de la limosna. Respecto a la educación, al poco de la fundación de la institución se crearon las Escuelas Patrióticas, en las que se enseñaba a trabajar el lino, el cáñamo, el algodón y la lana.

En 1786 el rey Carlos III se dirige al Consejo para que «proponga medios para animar y hacer útiles a las Sociedades Económicas " ${ }^{6}$. Para ello se debía informar sobre las causas de la decadencia, de la asistencia de socios, del desarrollo de sus actividades y proponer «los medios que estimasen prudentes y efectivos para aficionar á las personas zelosas y arraygadas en estos establecimientos tan útiles a la Monarquía" ${ }^{7}$. Parece que el entusiasmo de los primeros tiempos se había apagado en algunas sociedades, aunque para Sarrailh, la institución madrileña seguía gozando de buena salud coincidiendo con la presidencia de Jovellanos ${ }^{8}$. Todavía durante el reinado de Carlos IV la Sociedad Matritense cumplió su misión y siguió siendo un agente activo de progreso $0^{9}$. El suceso más significativo, por su trascendencia posterior, fue la aprobación del Informe sobre la ley agraria, realizado por Melchor Gaspar de Jovellanos dirigido al Consejo de Castilla el 3 de noviembre de 1794 y publicado por la entidad en $1795^{10}$.

El inicio del siglo XIX coincidió con cierto enfriamiento del pensamiento ilustrado, pero la entidad continuó con sus iniciativas, entre las que se pueden citar el expediente sobre la conveniencia de extender los plantíos en las cercanías de Madrid, el establecimiento de comidas económicas, la creación de la Escuela de Sordomudos y la de Taquigrafía. El problema principal que tuvo que abordar la matritense y que se convirtió en crónico con el tiempo, empezó a ser el económico, ya que al no poseer locales propios para el ejercicio de sus actividades, tanto educativas como de beneficencia, tenía que hacer frente a los alquileres de los edificios donde estaban

5 A. M. DEL Moral Roncal: "Los socios militares de la Real Sociedad Económica Matritense de Amigos del País (1785-1815)m, en Militaria. Revista de Cultura Militar, $n .{ }^{\circ} 6$, Real Asociación de Amigos de los Museos Militares, Ed. Complutense, Madrid, 1994, p. 108.

6 Real órden de 28 de junio de 1786 en Novisima Recopilacion de las leyes de España mandada formar por el rey Carlos IV, t. IV, Imp. Real, Madrid, 1805-1807, p. 173.

7 Ibidem.

8 J. SarRailh: ob. cit., p. 272. Gaspar Melchor de Jovellanos fue director de la Sociedad en 1785.

9 J. SARRAllH: ob. cit., p. 289.

10 El director de la Sociedad era Manuel Godoy, el Príncipe de la Paz. Fue sucesivamente reelegido desde 1792 hasta 1797 y posteriormente en 1807, asi pues la aprobación del Informe sobre la ley agraria por la Sociedad tuvo que contar con su apoyo. Jovellanos fue destituido como ministro de Gracia y Justicia en 1798. 
situadas, además de los sueldos de los profesores y los empleados y los propios gastos de gestión de la institución. Las cuotas de los socios no eran suficientes para autofinanciarse y ya varias veces hubo que pedir al Rey aportaciones extraordinarias que, en la difícil coyuntura de guerra casi continua y crisis hacendística en el que se encontró España entre 1793 y 1808, no eran fáciles de conseguir ${ }^{11}$.

\section{LA SOCIEDAD ECÓNOMICA MATRITENSE DURANTE EL REINADO DE FERNANDO VIII}

A finales de 1806, Manuel Godoy, el Príncipe de la Paz, habia sido elegido presidente de la sociedad ${ }^{12}$. La entidad gozaba de una lánguida existencia, dedicada a sus quehaceres, sin preocuparse de los acontecimientos políticos. Nada hacía prever la convulsión que iba a suponer en España la entrada de las tropas de Napoleón. En los primeros momentos de la Guerra de la Independencia la actividad de la corporación estuvo condicionada por los sucesos políticos del país. Las sucesivas ocupaciones de Madrid tanto por los franceses como por los ejércitos españoles alteraron sustancialmente la tranquilidad de la que hasta entonces había gozado.

A finales de 1810 se produce el acercamiento de los afrancesados hacia la matritense, que comenzó con la asistencia mas o menos asidua a las Juntas, de afiliados comprometidos con José Bonaparte y que ocupaban cargos de importancia en el Gobierno ${ }^{13}$. En octubre de 1810 volvieron a celebrarse elecciones (no se celebraban desde 1807$)^{14}$. A continuación se inició el proceso de modificación de Estatutos y admisión de socios para que fueran acordes a la Constitución de Bayona, que fueron aprobados en $1812^{15}$. Por último, comenzaron a incorporarse personas comprometidas con el gobierno de José Bonaparte ${ }^{16}$.

11 Por ejemplo, en 1796 se planteó el problema de tener que cerrar las Escuelas Patríticas por falta de fondos para atenderlas. Gracias a las gestiones de Godoy y la marquesa de Truillas ante el Rey se superó la crisis financiera y las escuelas consiguieron sobrevivir. P. DE DEMERSON: “Las Escuelas Patrióticas entre 1787 y 1808", en Las Reales Sociedades Económicas de Amigos del País y su obra, Patronato José María Quadrado (CSIC), San Sebastián, 1972, p. 201.

12 Archivo de la Real Sociedad Matritense de Amigos del Pais (ARSEM), Libro de Actas de las Juntas de la Sociedad 110/33, Junta de Dirección de 22-11-1806. A finales de 1807 Godoy volvió a ser reelegido, pero rehusó por sus múltiples ocupaciones. Tras varios intentos para convencerto, finalmente se le aceptó la renuncia y fue elegido el Duque de Aliaga (Duque de Híjar, tras el fallecimiento de su padre en 1808), ARSEM, Idem; Junta de Dirección de 19-12-1807.

${ }^{13}$ Entre los asistentes a partir del último trimestre de 1809 es normal encontrar a José Mazarredo, Francisco Cabarrús (conde de Cabarrús), José Martínez de Hervás (marqués de Almenara) y Manuel María Cambronero. ARSEM, Libro de Actas de las Juntas de la Sociedad 110/36, Juntas de Dirección de 14-10-1809 en adelante.

${ }_{14}$ ARSEM, Idem, Junta de Dirección de 27-10-1810. Fueron elegidos como director de la sociedad el marqués de Almenara y subdirector José Mazarredo, dos importantes afrancesados.

${ }^{15}$ José Bonaparte había firmado el Decreto de fecha 24 de diciembre de 1810 sobre la admisión de socios, como consecuencia se formó una comisión para la modificación de los Estatutos. ARSEM, ldem; Junta de Dirección de 5-1-1811.

${ }^{16}$ Muchos de los inscritos eran empleados del Ministerio del Interior, que ocupaba el marqués de Almenara (director de la Sociedad), por lo que más parece que hubo alguna presión por parte del ministro hacia sus subalternos. ARSEM, Idem; Juntas de Dirección de 12-1-1811 a 6-4-1811. 
Las actividades de la sociedad continuaron en mayor o menor medida, de manera que siguieron trabajando los asociados en elaborar informes y se ofrecieron premios para la realizar memorias para el fomento de la agricultura y ganadería. Donde sí se observa diferencia respecto al periodo anterior es en el aspecto de la educación. Las dificultades económicas de la institución y los trastornos de la guerra obligaron a cerrar el Colegio de niños sordomudos y la Escuela de Taquigratia.

El 17 de marzo de 1813 José Bonaparte abandonó Madrid para no volver más y con él las personas comprometidas con las autoridades francesas. A partir de este momento, se observa un proceso de renovación de socios y se acuerdan nuevos nombramientos. La sociedad presenta una intensa actividad de congraciarse con las nuevas autoridades constitucionales, que consistió en la anulación de los Estatutos aprobados bajo el dominio francés y la propuesta de creación de una comisión que elaborase unos nuevos Estatutos de acuerdo a la Constitución y al Decreto de las Cortes de 8 de junio de 1813 para el desarrollo de las Sociedades económicas ${ }^{17}$. Dichos Estatutos se aprobarán en la Junta de 5 de marzo de 1814. La afluencia de afiliados a las Juntas y la cantidad de iniciativas da a entender un periodo de cierta esperanza hacia el futuro. Además, se incorporaron algunos liberales conocidos. Otra iniciativa fue el establecimientos de una cátedra de Economía Política ${ }^{18}$.

El día 13 de mayo de 1814 Fernando VII entró en Madrid, como Rey absoluto, ya que previamente había anulado toda la obra de las Cortes de Cádiz. Comenzará otra etapa en la vida de la sociedad. La tarea que tenía por delante la corporación para deshacer todo lo realizado en los años de la guerra y volver a la situación anterior a 1808 era inmensa y todo esto debía compatibilizarse con los objetivos de la sociedad de fomento de la economía y las actividades asistenciales. Para el cumplimiento de sus fines, Fernando concedió una pensión de 3.000 reales anuales como socio protector que se añadió a las de 1.500 reales que tenían asignadas por los Infantes Don Carlos y Don Antonio Pascual ${ }^{19}$.

Fernando VII al favorecer a la matritense debió pensar que, a pesar de los numerosos socios afrancesados y liberales huidos o encarcelados, no se trataba de una corporación peligrosa para su trono. Además tomó medidas, ya que resolvió que fueran «borrados de las Reales Academias y Sociedades Patrioticas todos los individuos comprendidos en los articulos del decreto de 30 de mayo último" ${ }^{20}$. $\mathrm{Si}$

17 Decreto de 8 de Junio de 1813 sobre el establecimiento de cátedras de agricultura, y de sociedades económicas en Colección De Los Decretos Y Ordenes que han expedido las Cortes Generales y Extraordinarias, t. IV, Imp. Nacional, Cádiz, 1813, pp. 84-85.

18 ARSEM, Libro de Actas de las Juntas de la Sociedad 110/38, Junta de Dirección de 7-1-1814.

19 ARSEM, Idem; Junta de Dirección de 30-7-1814.

20 ARSEM, Idem; Junta de Dirección de 19-11-1814. Se refiere al Decreto de 30 de mayo de 1814 sobre los afrancesados. En Juntas posteriores (26-11-1814, 17-12-1814 y 21-1-1815) se habla de que se ha elaborado una lista que comprende a «45 individuos que han seguido el partido intruso, 109 no se sabe si son vivos o muertos y algunos pendientes de purificación". Esta lista no se ha encontrado en el archivo, ya que en el expediente sólo aparece la lista relativa a la Junta de Señoras en el que figuran dos 
aparecía como un rey ilustrado, como sus antecesores, la oposición sería menor. Además también la entidad hizo cierta labor de aproximación a las nuevas autoridades durante todo el periodo ya que se concedió el título de socio de mérito a algunos ministros y altos funcionarios. El primer signo de normalidad fue la reapertura del Colegio de niños sordomudos ${ }^{21}$. Después se abrió la cátedra de Economía política $^{22}$, continuaron las clases de la Escuela de Taquigrafía, solicitaron al Rey que aprobase el Plan de restablecimiento y uniformidad de los Cuerpos de las Reales Sociedades Economicas ${ }^{23}$ y se aprobaron nuevos Estatutos ${ }^{24}$.

En estos años la entidad volvió prácticamente a la normalidad. Hubo numerosas solicitudes de admisión y continuaron trabajos anteriores que se habían dejado a medias por la guerra. Los partícipes se esforzaron en presentar sus informes y memorias. Se revisaron los privilegios de patentes que envio el Ministerio de Estado, volvieron a editar el Informe sobre la Ley agraria y siguieron con interés diversos descubrimientos que se publicaban en periódicos extranjeros. Además la Sociedad de Madrid tuvo a su cargo la tramitación de permisos para la apertura de nuevas sociedades en el resto de España y canalizaba la presentación de informes de dichas corporaciones al Gobierno.

Los años de 1816 a 1818 la institución tuvo un éxito como no había tenido anteriormente, la inscripción de socios fue numerosa y empezaron a surgir voces para que se detuviera la avalancha de afiliación, pues se temía que no todos los nuevos ingresos se acercasen con propósitos sinceros de trabajar para ella ${ }^{25}$. Entre los ingresos del año 1818 figura el Infante Don Francisco de Paula, que fue nombrado protector $e$ incluso elegido director de la matritense, aunque finalmente no aceptó el cargo y se celebraron nuevas elecciones ${ }^{26}$.

En los primeros meses del Trienio Liberal (1820-1823) se observa una actividad intensa. Uno de los primeros proyectos consistió en la modificación de los Estatutos para adaptarlos al régimen constitucional. La aceptación de la Constitución de Cádiz por el Rey había desencadenado un sentimiento de esperanza en la mayoría del país, al que no fueron ajenos los socios. Por ello, se felicita al Rey en una Audiencia el día 28 de mayo de 1820 en la que se manifestó "el júbilo de la Sociedad por la adopción de un sistema tan análogo a sus principios, y los deseos de contribuir con sus luces y sus tareas a la prosperidad nacional, a lo que contestó el Rey, que apreciaba la memoria de este cuerpo económico y sus importantes ocu-

\footnotetext{
personas que, a pesar de haberse incorpordo a dicha Junta durante la dominación francesa, no estaban comprometidas con los franceses. No hay que olvidar que el Decreto citado incluía a las esposas que habian huido con sus maridos a Francia.

21 ARSEM, Idem; Junta de Dirección de 16-10-1814 y M. EsPADAs BuRgos: «La Sociedad Económica Matritense y el hambre de 1812", en Las Reales Sociedades Económicas de Amigos del País y su obra, Patronato José María Quadrado (CSIC), San Sebastián, 1972, p. 222.

22 ARSEM, Idem; Junta de Dirección de 8-5-1815.

23 ARSEM, Idem; Junta de Dirección de 3-6-1815.

24 ARSEM, Libro de Actas de las Juntas de la Sociedad 110/39, Junta de Dirección de 22-7-1815.

${ }^{25}$ ARSEM, Legajo 232/2, 241/14 y 246/4.

${ }^{26}$ ARSEM, Libro de Actas de las Juntas de la Sociedad 110/42, Junta de Dirección de 6-11-1818.
} 
paciones ${ }^{27}$. Durante los dos años siguientes se observa una cierta disminución del trabajo de la entidad. Las funciones educativas habían pasado a ser competencia del Gobierno y las dificultades económicas obligaron a una restricción de las tareas. Aun así, todavía hubo iniciativas individuales de asociados que se dedicaban incansablemente a la corporación.

El año 1823 es el de la caída del régimen constitucional. La inestabilidad política repercutió en la labor, que decae por la ausencia de participantes. Son continuas en las juntas las alusiones de integrantes que comunican su ausencia de Madrid. Durante varias semanas, desde el mes de abril de 1823 no se celebraron juntas por falta de quórum y cuando se reúnen no asisten más de seis o siete. Por fin, se decide formar una comisión para felicitar a la Regencia, como se habia hecho hasta entonces en los sucesivos vaivenes políticos ${ }^{28}$. Pero esta vez no es lo mismo, ya que "se le prohibió el paso hasta que no fuera rehabilitada". Después de varios intentos al final fue recibida ${ }^{29}$. Después de octubre de 1823 ya no hay más actas de la Junta de Dirección.

¿Qué pasó a partir de esa fecha? La siguiente Junta se celebró el 7 de noviembre de 1833, exactamente diez años después, y lleva el título de Junta extraordinaria de reinstalación de la Sociedad ${ }^{\beta 0}$. Durante esos diez años los trabajos de la institución fueron mínimos. Por un lado, confundida entre el resto de Sociedades Patrióticas y Secretas que habían proliferado durante el Trienio estaba prohibida por las autoridades del Ayuntamiento de Madrid. Por otro lado, al ser necesaria para resolver ciertas competencias del Gobierno, como los informes de privilegios de patentes, era tolerada cierta actividad. Además, continuaron las actividades educativas como la Escuela de Taquigrafía y la Cátedra de Economía Política ${ }^{31}$. En un estado de semihibernación, solo la dedicación de unos pocos asociados, trabajando lo que les era posible y evitando cualquier motivación política, evitaron su desaparición

27 ARSEM, Idem; Junta de Dirección de 3-6-1820.

${ }^{28}$ ARSEM, Idem; Junta de Dirección 28-6-1823. La Regencia absolutista presidida por el Duque del Infantado se habia instalado en Madrid dos días antes.

29 ARSEM, Ibidem.

30 ARSEM, Libro de Actas de las Juntas de la Sociedad 110/45, Junta de reinstalación de la Sociedad de 7-11-1833.

${ }_{31}$ ARSEM, Legajo 317/6. Memoria de las tareas de la Sociedad economica matritense desde 1823 en que suspendió sus Sesiones, hasta Noviembre de 1833 en que fue reinstalada; leida en la Sesion de 20 de Dic. de 1834 por D. Francisco Lopez de Olavarrieta, censor de la misma corporación, encargado de formarla por acuerdo de 8 de Noviembre del mismo año de 1834. La explicación de lo ocurrido desde el punto de vista de los propios socios fue la siguiente: «No era posible que el espiritu de vandalismo que tantos establecimientos utiles destruyó en el aciago año de 1823 perdonase á la Sociedad económica Matritense. Aunque sin expresa orden del Gobierno para ello, esta patriótica Corporación se vió (sic) en la dolorosa necesidad de suspender sus reuniones; pero por una anomalía inconcebible y solo posible en las inconsecuencias y abandono de los Gobiernos absolutos, continuaron abiertas las cátedras de Economía Política y Taquigrafía á las que concurrió siempre una juventud numerosa. Eminentes por su importancia y por los peligros de la época fueron los servicios de algunos socios que conservaron del naufragio jeneral (sic) estos y otros restos preciosos de la ilustración y de la libertad, y la aciaga época de los diez años no es ciertamente la menos gloriosa para una corporación que el público consideraba disuelta y que en realidad no tenía otra vida que la que recibia de los esfuerzos aislados de algunos beneméritos individuos". 
total. El Decreto de rehabilitación fue firmado por la Reina Gobernadora María Cristina, inmediatamente después de haber muerto Fernando VII en 1833.

\section{LA JUNTA DE DAMAS O JUNTA DE HONOR Y MÉRITO}

La Junta de Damas fue autorizada por el Rey en 1787. En ella «las mujeres ilustradas de buena voluntad se harían cargo de aquellos asuntos que los miembros de la Sociedad estimaban poderles confiar „32. Esta Junta, llamada también de Honor y Mérito, se organizaba como una sección independiente dentro de la Sociedad matritense. Admitía sus propias socias, celebraba sus reuniones semanales y elegía sus cargos. Las actas de las juntas debían ser aprobadas en la Junta de Dirección, que era el órgano superior de la corporación. En todo el periodo revisado (1806-1823) no se observaron apenas conflictos ni intromisiones por parte de los órganos rectores de la entidad. Además, las Señoras, como habitualmente son nombradas, eran componentes de pleno de derecho de la sociedad, iguales a sus compañeros masculinos. Entre sus derechos destaca el de voto en las elecciones a los cargos o oficios de la corporación y que además también podían ser elegidas para dichos cargos.

El primer encargo por parte de la Junta de Dirección consistió en el «cuidado y vigilancia de las Escuelas patrióticas " ${ }^{33}$. Dichas escuelas se habían creado en 1776 para buscar una salida profesional a la juventud pobre de la ciudad. Se trataba de evitar que cayesen en la mendicidad mediante la educación y el aprendizaje de una profesión que les permitiera acceder a un puesto de trabajo como artesanos. Bajo la protección del rey Carlos III se establecieron en Madrid cuatro escuelas gratuitas, en las que en un periodo de tres años se enseñaba un programa completo de aprendizaje en el que el aspecto principal era el hilado, fabricación de telas y los conocimientos teóricos y prácticos de la tejeduría. La formación de completaba con la enseñanza de lectura, escritura, cuentas y religión.

Nada más hacerse cargo la Junta de Damas de dichos establecimientos se introdujeron algunas reformas en la enseñanza que consistieron en añadir el aprendizaje de bordados, punto y lencería, especialidades más útiles de cara a la inserción laboral. Se aprobó un nuevo Reglamento para el funcionamiento de dichas escuelas y los resultados positivos no se hicieron esperar. Antes de finales de siglo se abrieron nuevas escuelas especializadas, bajo la supervisión de la Junta de Honor y Mérito, como la Escuela de Bordados, la de Encajes y la de Flores Artificiales, que se añadieron a las cuatro patrióticas que ya funcionaban ${ }^{34}$. También la Escuela de Educación concebido como colegio para niñas, tanto internas como externas. Se trataba de una enseñanza no gratuita, en el que sus alumnas procedian de fa-

32 P. De Demerson: ob. cit., p. 196.

33 Ibidem.

34 Sobre el funcionamiento y evolución de las escuelas patrióticas y el resto de escuelas populares bajo la supervisión de la Junta de Damas, véase: O. NEGRín FAJARDO: La educación popular en la España de la segunda mitad del siglo XVIII, UNED, Madrid. 
milias de cierto status económico, aunque la enseñanza de carácter general que se proporcionaba en dicho establecimiento no fuera muy diferente de las anteriores.

Durante la Guerra de la Independencia, el esfuerzo de la Junta de Damas por mantener su actividad fue considerable, ya que algunas escuelas pudieron mantenerse abiertas, a pesar de las dificultades financieras, hasta 1811. La separación de los fondos de la tesorería de la propia Junta de los generales de la sociedad, explica la razón por la que las Damas lograron atender a las necesidades de los establecimientos bajo su custodia de forma independiente. También durante esos años se hicieron cargo de la supervisión de la inclusa.

Tras la vuelta de Fernando VII, la Junta sufrió la ausencia de algunas de las socias más activas durante la guerra, que se vieron obligadas a seguir a sus familiares a Francia. Pero no por ello se resintió su trabajo. Continuaron las labores de supervisión y gestión de las escuelas reabiertas y fruto de esta labor consiguieron que tanto la reina Isabel de Braganza, esposa de Fernando VII, como las infantas fueran incorporadas como protectoras. En los últimos años del reinado de Fernando VII, al tratarse de una institución dedicada íntegramente a las labores de educación y beneficencia siguió desarrollando sus tareas sin verse afectada por los cambios políticos, al contrario que el resto de la sociedad. Uno de los logros de aquellos años consistió en que el propio Rey financiase las obras de ensanche del Colegio de la Paz en 1828, bajo la presidencia de la Duquesa de Gor.

\section{LOS SOCIOS DE LA REAL SOCIEDAD ECONÓMICA MATRITENSE}

La capacidad de la Sociedad Económica Matritense para desarrollar sus actividades se debía al trabajo que las personas que la integraban estuvieran dispuestas a desarrollar para la institución. Por eso los periodos en los que hubo menor afluencia de socios, que coincidieron con las dificultades políticas que vivió el país, las tareas realizadas se resintieron en cierto modo, aunque sin llegar nunca a verse en la necesidad de disolver la corporación, ya que incluso en los peores tiempos hubo afiliados que mantuvieron vivo, aunque con limitaciones, el espiritu de la institución.

Durante todo este periodo hubo varias modificaciones de Estatutos para adaptarse a los cambios políticos, aunque en el aspecto de los socios apenas hubo variación ${ }^{35}$. Las categorías recibieron denominaciones distintas, según los Estatutos vigentes en cada momento, pero pueden reducirse a las cuatro siguientes:

${ }^{35}$ No se ha podido analizar con detalle los Estatutos. Ya se hizo referencia anteriormente a que en el acceso a los cargos directivos no estaban excluidas las mujeres. De hecho, la duquesa de Frías fue elegida subdirectora de la sociedad en 1808 y no consta en las Juntas posteriores que dimitiese. ARSEM, Libro de Actas de las Juntas de la Sociedad 110/33, Junta de Dirección de 30-1-1808. También la marquesa de Villafranca fue elegida en una ocasión tesorera de la sociedad, aunque no aceptó el cargo. ARSEM Libro de Actas de las Juntas de la Sociedad 110/38, Junta de Dirección de 10-11-1814. Tampoco hubo problemas en aceptar socios extranjeros, entre los cuales hubo varios de mérito, además de corresponsales. 
- Socio protector: se reservaba a los componentes de la familia real.

- Socio de mérito: en principio se concedía a personas reconocidas por su trayectoria artística o científica y luego también política, a las que se incorporaba tras votación de los integantes de la institución. También se incluyen en esta categoría los premiados en los concursos de Memorias, así como aquellos partícipes que destacaban por su trabajo para la sociedad propuestos para esta condición por sus compañeros.

- Socio corresponsal: abarca a aquellos miembros que no residian en Madrid. Tras su inscripción se obligaban a trabajar para la corporación, comunicando noticias o realizando memorias.

- Socio contribuyente: en esta categoría se incluyen la mayoría de los asociados. También recibieron el nombre de socios de número. Se adscribían a alguna de las tres Clases o Juntas en que se organizaba la sociedad (Agricultura, Comercio y Artes y Oficios) y estaban obligados a trabajar para la entidad, desarrollando los trabajos o actividades que se les encargaba en la Clase a la que pertenecían o por la Junta de Dirección.

El proceso de admisión no sufrió variaciones de consideración, a pesar de las variaciones de Estatutos que sucedieron en el periodo analizado. Solo durante el tiempo que estuvieron vigentes los Estatutos aprobados por José I, fue más sencillo. La incorporación se iniciaba con la solicitud por parte del aspirante dirigida al director. Éste, en la primera Junta de Dirección después de recepción del escrito, daba cuenta de la existencia de la solicitud sin desvelar el nombre del candidato.

En la siguiente Junta semanal se nombraban los tres informantes secretos por sorteo que debían emitir un informe en el plazo más breve posible sobre la persona del solicitante. Normalmente, los encargados consultaban a personas que conocían al candidato o que se movían en los mismos círculos. No hay que olvidar que el Madrid de esta época tenía unos $\mathbf{2 0 0 . 0 0 0}$ habitantes y todos o casi todos los socios pertenecían a la élite de la sociedad, es decir, una minoría ilustrada entresacada de ciertas clases de la sociedad madrileña (nobleza, clero o burguesía) que frecuentaba los mismos ambientes o que coincidian en ciertas profesiones (profesores, científicos, abogados, militares, escritores, funcionarios 0 artistas) ${ }^{36}$.

Tras la elaboración de los informes secretos y siempre que fueran favorabies, que era lo normal, se procedía en la junta a nombrar a los informantes públicos. Una vez cumplimentados, en caso de ser positivos, se pasaba a votación la admisión del futuro integrante. Si la votación era favorable por la mayoría de los asistentes a dicha Junta se le inscribía. El proceso era el mismo para los socios de mérito y para los corresponsales, en este último caso con las limitaciones que la

${ }^{36}$ De todos los aspirantes a socios de los que se conocen sus profesiones o empleos, solo figura un caso en que la profesión sea labrador. Además, fue inscrito y al poco tiempo excluido de la Sociedad ya que el interesado no quiso pagar la cuota de entrada, establecida en 120 reales. 
falta de conocimiento por carecer de residencia en Madrid podía suponer. Pero como la labor de éstos últimos se limitaba a enviar informes y noticias no hubo problemas en incorporar a aquellos que lo solicitaron.

Como se ha dicho lo normal era que los informes fueran favorables, por eso son constantes en las juntas las alusiones por parte del censor de la corporación para que los informantes tuvieran cuidado y se tomasen la molestia de recabar información al redactar los informes. De hecho en toda la documentación analizada entre los años 1806-1823, fechas en las que se integraron 302 partícipes, solo se da un caso en el que la votación tuvo resultado negativo respecto al aspirante y hubo doce solicitudes de futuros componentes que no llegaron a concluir el expediente de admisión, debido a causas diversas, incluida la desidia por parte de los encargados, más que los informes fueran desfavorables.

Una vez admitido el candidato, se emitía el título de socio, que se le entregaba, junto a un ejemplar de los Estatutos. El nuevo afiliado debía satisfacer por adelantado la contribución anual, establecida en 120 reales. Los socios de mérito y los corresponsales estaban exentos de pagar la cuota de entrada. Después el nuevo miembro tenía la obligación de presentarse y adscribirse a una de las Clases (agricultura, comercio o artes y oficios) en función de sus preferencias.

Durante el periodo en que estuvieron vigentes los Estatutos aprobados por José Bonaparte, el trámite de los informantes fue suprimido, de manera que a medida que se recibían las solicitudes se informaba en la Juntas y a continuación se procedía a la votación para la aceptación del candidato. En los años del Trienio Liberal se introdujo una modificación, ya que después de ser aceptado el recién llegado debía jurar la Constitución. Incluso hubo una propuesta de quien fue director de la sociedad poco después, el duque de Noblejas, para que en los informes secretos se expresara «si los candidatos a socio eran adictos al sistema constitucional ${ }^{37}$. Dicha propuesta al final no prosperó.

\section{EVOLUCIÓN DE LOS SOCIOS DE LA INSTITUCIÓN}

La reconstrucción de Catálogo de la sociedad ha arrojado un censo de aproximadamente 500 personas a lo largo del periodo considerado ${ }^{38}$. De ellos 302 fue-

${ }^{37}$ ARSEM, Libro de Actas de las Juntas de la Sociedad 110/44, Junta de Dirección de 25-11-1820.

38 Para la elaboración del Catálogo de socios se han revisado los Libros de Actas de la Junta de Dirección de la Real Sociedad Matritense de Amigos del País en el periodo considerado (desde 1806 a 1823). ARSEM, Libro de Actas de las Juntas de la Sociedad 110/33 a 110/44. Además se han consultado varias listas de socios: 1. Copia de la lista de los Sres. Individuos de la Real Sociedad Economica de esta Corte que se pasó al $M{ }^{\circ}$ del Interior en 1 de Diciembre de 1809 a consecuencia de la Orden Comunicada al Cuerpo por dicho Ministerio en 13 de Octubre ultimo. Esta relación fue completada posteriormente con las incorporaciones que se fueron produciendo hasta el día 24 de enero de 1811. ARSEM, Legajo 206/18; 2. Lista de los Sres. Individuos de número, supernumerarios y honorarios de la Real Sociedad Economica matritense, residentes en Madrid en el presente de la fecha sacado del Catalogo original y confrontada con la que existe en la Tesoreria del Cuerpo para la cobranza de la Contribucion 
ron aceptados entre los años 1806 y 1823 , y 185 han sido localizados en alguna de las distintas listas consultadas como inscritos antes de 1806 . Además hay seis sobre los que se comunica su fallecimiento en los años 1807 y 1808 y por tanto no figuran en las listas consultadas (la primera es de 13-10-1809) y otros dos que no aparecen ni en las incorporaciones ni en las listas, sobre los que se comunicó su baja entre 1813 y 1815.

También aparece algún nombre más esporádicamente como asistente a alguna Junta, pero al no tener seguridad de sí se trataba de un socio de la institución o asistente en su calidad de formar parte a alguna diputación en Madrid de una Sociedad Económica de otra provincia no se han considerado. Respecto a 13 no llegaron a integrar la entidad, al no concluirse sus expedientes de entrada o haberse negado por votación el ingreso. Esto suma un total de 489 personas localizadas de las que se tiene información veraz de su pertenencia entre 1808 y 1823, por figurar en alguna de las listas o haber sido aceptados entre 1806 y $1823^{39}$.

La evolución de las admisiones fue la siguiente:

\begin{tabular}{cc|cc|cc}
\hline Año & N. $^{\circ}$ de altas & Año & N.o de altas & Año & $N^{\circ}$ de altas \\
\hline 1806 & 8 & 1812 & 3 & 1818 & 78 \\
1807 & 4 & 1813 & 8 & 1819 & 19 \\
1808 & 1 & 1814 & 23 & 1820 & 7 \\
1809 & 2 & 1815 & 22 & 1821 & 15 \\
1810 & 3 & 1816 & 28 & 1822 & 12 \\
1811 & 28 & 1817 & 41 & 1823 & - \\
\hline
\end{tabular}

Para saber aproximadamente los socios efectivos con los que contaba la corporación durante todo el periodo ha habido que considerar varias informaciones. Por un lado, en la Junta de 22-8-1807 se dice que la matritense contaba en ese momento con 181 miembros. En esa fecha se habia hecho una revisión del Catálogo, excluyendo a aquellos que debian tres contribuciones anuales. La lista de José Bonaparte a 31-10-1809 cuenta con 165 nombres, incorporados antes de esa fecha, de los cuales solo 2 fueron inscritos entre septiembre de 1807 y octubre de

anual, por orden de su antigüedad. 31 de octubre de 1816. ARSEM, Legajo 235/22; 3. Catalogo de los Sres. Individuos de la Real Sociedad Economica de Amigos del Pais de Madrid desde su ereccion en el año 1775 hasta enero de 1818. ARSEM, Legajo 276/4; y 4. Catálogo de los Señores que componen la Sociedad económica Matritense de Amigos del Pais en 10 de Octubre de 1835. ARSEM, Legajo 317/3.

39 En cuanto a los inscritos antes de 1806, las discrepancias surgen por no haberse podido consultar las actas de las Juntas, ya que en todas las listas analizadas aparecen nombres nuevos. Por tanto, de momento se han dado por buenas todas las relaciones por no tener todavía elementos de juicio suficientes para saber si contienen errores. 
1809. ¿A que se debe la diferencia de 18 entre una y otra? En principio habría que achacarlo a un error en la lista de 1809, ya que en las listas de 1816 y 1818 aparecen 22 personas de antigüedad superior a 1806 que no están en la de 1809. Todavia en la lista de 1835 aparecen dos personas que no figuran en ninguna de las listas anteriores. En este último caso la explicación es clara, ya que se incluyeron a todos aquellos socios de los que se tenía conocimiento de su existencia en 1835 que habían pertenecido en algún momento a la sociedad, independientemente de la causa de la baja posterior.

Por el decreto de 30-5-1814 fueron borrados 45 afiliados por afrancesados, de 109 no se tenían noticias y del resto, es decir, la cantidad de socios efectivos, aunque algunos estaban pendientes de purificación ${ }^{40}$, estaría en torno a unos 137 asociados (98 anteriores a 1806 y 39 entre 1806 y 1814), ya que la reconstrucción del censo hasta 17-12-1814 según todas las listas da en esa fecha un total de 298 personas. De éstas, se había comunicado el fallecimiento de siete durante el periodo de 1808-1814.

Considerando como buena la cifra de 137 asociados a principios de 1815, hay que pasar a analizar la lista de enero de 1818. Según dicha relación, hasta ese momento había 231 socios (la última persona de la lista fue incorporada en 24-1. 1818). La reconstrucción del censo arroja la cifra de 239. La diferencia se debe a que en estos tres años se comunicó el fallecimiento de varios miembros y otros se dieron de baja. Además se da el caso de alguno que fue borrado del Catálogo por afrancesado, que volvió a España y fue de nuevo incluido en la sociedad. El año de 1818 fue el mejor en cuanto a las admisiones. La entidad llegó a duplicar prácticamente sus efectivos entre los años 1818 y 1819 , pasando de una media en torno a 150 socios entre 1807 y 1815 a superar los 300 en los años 1818 a 1820. Los años siguientes hubo una menor afluencia de incorporaciones. La última lista consultada es de 1835, y todavía en esa fecha figuraban 136 personas cuya entrada se produjo antes de 1823.

La investigación respecto a las socias de la Junta de Damas ha resultado más difícil, ya que solo se dispone de dos listas ${ }^{41}$ : una de 4-7-1812, que se refiere a las que residían en esos momentos en Madrid, en la que aparecen 17 personas (de éstas, siete no figuran en la lista posterior, algunas por haber fallecido y el res-

${ }^{40}$ Según el citado decreto, las personas que habian jurado obediencia a José Bonaparte o colaborado con su Gobierno, aunque se hubieran visto obligados a ello, debian someterse a un proceso de purificación que juzgaba su conducta. Solo en el caso que fueran declarados inocentes se les restituirian los empleos, títulos, cargos o distinciones que tuvieran antes de la invasión francesa.

41 Para elaborar el censo de las socias de la Junta de Damas se han tenido en cuenta, por un lado las comunicaciones que la secretaria de dicha Junta enviaba a la Junta de Dirección sobre la admisión de nuevas socias. Con esta información se conocen las nuevas socias entre 1806 y 1823 . Por otro lado, las dos únicas listas encontradas en el archivo, referidas al periodo objeto de estudio, que son las siguientes: 1. Catálogo de Socias Honor y Mérito. Esta lista tiene fecha de 4 de julio de 1812 y solo incluye a las socias residentes en dicha fecha en Madrid. ARSEM, Legajo 213/27; 2. Lista de los Individuos de la Junta de Señoras de honor y mérito Unidas a la Real S.E. de amigos del Pais desde su creación en 1786 hasta enero de 1818 para insertar en la Guia de Sociedades. ARSEM, Legajo 276/4. 
to por haber sido borradas por afrancesadas ${ }^{42}$ ); y otra de 28-1-1818 con 57 personas (de las cuales 38 son anteriores a 1807). Las inscripciones producidas entre 1807 y 1823 son un total de 32 socias. Así el censo total del periodo arroja la cifra de 77 socias, aunque la lista es incompleta debido a que, cuando se elaboró la primera relación en 1812, la mayoría no residian en Madrid, pues se hizo en plena Guerra de la Independencia.

\section{LAS RELACIONES DE PARENTESCO DE LOS SOCIOS DE LA INSTITUCIÓN}

Al tratarse de una corporación que aceptaba miembros de ambos sexos, es lógico que entre sus afiliados se encuentren varios matrimonios. Esta situación es perceptible casi siempre entre asociados pertenecientes a la nobleza. En este grupo social es donde se han observado mayores lazos de parentesco, no sólo de afinidad sino también de consanguinidad. Hay que señalar el esfuerzo que ha supuesto conocer los nombres de muchas de las personas, pues los componentes de la aristocracia solían nombrarse por sus títulos, lo que supone la dificultad añadida de que podían cambiar su título en función de herencia o matrimonio ${ }^{43}$.

En segundo lugar, hay que hacer referencia a la coincidencia de apellidos, que en principio ha delatado la existencia de padres o hermanos, en muchos casos sólo se ha podido averiguar si en algún momento, a través de la documentación manejada, se ha hecho relación al parentesco. Otras veces la consulta de la bibliografía es la que ha dado la clave de estas vinculaciones. De todas maneras la investigación de los nexos familiares más completos se ha conseguido con los miembros de la familia real, que se estudiarán en un apartado concreto, y en personas de la aristocracia.

Además, al haberse investigado un periodo de quince años (en los últimos diez años del reinado de Fernando VII no hubo nuevas inscripciones) ha sido imposible reconstruir familias de varias generaciones, por lo que el resultado es incompleto. Solo en casos muy significativos se ha podido relacionar con socios o socias anteriores o posteriores al periodo considerado.

42 En el decreto de proscripción de los afrancesados se incluía a las esposas que hubieran acompañado a sus maridos a Francia.

${ }^{43}$ Para la elaboración de las notas biográfica se ha utilizado, además de las enciclopedias de tipo general, la siguiente bibliografía: A. GIL NovALES: Diccionario Biográfico del Trienio Liberal, Ediciones EI MUseo Universal, Madrid, 1991; J. LÓPEZ TABAR: Los famosos traidores. LOS afrancesados durante la crisis del Antiguo Régimen (1808-1833), Biblioteca Nueva, Madrid, 2001; V. M. MárQUeZ DE LA PLATA, y L. VALERO DE BERnABE: El libro de oro de los Duques, Ediciones Iberoamericanas, Madrid, 1994; F. Ruiz CORTÉS, y F. SANCHEZ COBOS: Diccionario biográfico de personajes históricos del siglo XIX español, Rubiños, Madrid, 1998; J. VARELA DE LIMIA Y MENÉnDEZ: Los Directores de la Real Sociedad Económica Matritense de Amigos del País y las Presidentas de la Junta de Honor y mérito, Real Sociedad Económica Matritense de Amigos del País, Madrid, 1925. 


\subsection{Los miembros de la familia real y sus vinculaciones familiares}

Desde sus inicios, la institución tuvo una decidida protección real. El rey Carlos III al autorizarla instó a sus hijos a que fueran integrantes de la sociedad. Así, ya en 1775 formaron parte de la corporación como protectores, categoría especial reservada a la familia real, el propio rey Carlos III y sus hijos, el entonces príncipe de Asturias, Carlos (futuro Carlos IV), y el infante Antonio Pascual ${ }^{44}$. Posteriormente fueron incorporándose sucesivamente otros componentes de la familia.

En 1808, antes de la abdicación de Carlos IV figuraban como socios protectores el Rey (desde 1775), como se ha comentado anteriormente, su esposa la reina María Luisa de Parma y sus hijos la infanta Maria Luisa (llamada reina de Etruria), el príncipe de Asturias, Fernando (futuro Fernando VII), y el infante Don Carlos, que lo era desde 179545; además del citado infante Antonio Pascual, hermano del rey Carlos IV.

Durante los primeros años del reinado de Fernando VII se fueron incorporando a la entidad otros miembros. La protección de la familia real, no solo suponía el prestigio de la sociedad, sino que en la mayoría de las ocasiones llevaba aneja la concesión de pensiones anuales por parte de los protectores. Por ejemplo, Fernando señaló a favor de la corporación una pensión de 3.000 reales anuales como socio protector que se añadió a las de 1.500 reales que tenían asignadas por los infantes Don Carlos y Don Antonio Pascual ${ }^{46}$.

En 1816, Fernando contrajo su segundo matrimonio con Isabel de Braganza, a la vez que el infante Don Carlos lo hizo con la hermana de ésta, María Francisca de Asís. Las dos fueron aceptadas por la Junta de Honor y Mérito en dicho año47.

44 (Nápoles, 1755-Madrid, 1817). Hijo segundo de Carlos III, casó con su sobrina la infanta María Amalia, enviudando un año después. Se negó a figurar en política durante el reinado de Carlos IV y sólo cuando Fernando VII marchó a Bayona (10 de abril de 1808) consintió en aceptar la presidencia de la Junta Suprema que quedó encargada del gobierno del reino durante la ausencia del monarca. Marchó a Bayona durante la noche del dos de mayo. Asistió a las abdicaciones de Carlos IV y Fernando VII que entregaron la corona de España a Napoleón. Fue internado, junto a Fernando VII en Valençay, y no regresó a España hasta 1814, nombrándole entonces el rey Gran Almirante de Castilla. Fue aficionado a las ciencias y las artes y protector de la industria.

45 (Madrid, 1788-Trieste, 1855). Residió en Valençay durante la Guerra de la Independencia, junto al resto de la familia real española. Regresó a España en 1814 con su hermano Fernando. Tras la sublevación de Riego, estuvo al frente de la Junta constituida para la reforma de los negocios públicos. Aglutinó en torno a su persona a los sectores más reaccionarios del absolutismo. En 1833 al negarse a reconocer como princesa de Asturias a Isabel, hija primogénita de Fernando VII, fue desterrado a Portugal. A la muerte de Fernando VII dio un manifiesto en el que se proclamaba Rey de España con el nombre de Carlos V, que provocó que sus partidarios se levantaran en armas iniciándose la Guerra Carlista. En 1835 huyó de Inglaterra y entró en territorio español, logrando con su presencia recrudecer la guerra civil que duró hasta 1839, cuando se firmó el convenio de Vergara que puso fin a la lucha. Refugiado en Francia, el Gobierno le señaló la población de Bourges para su residencia, donde continuó hasta 1854, en que abdicó los derechos que alegaba a favor de su primogénito Carlos Luis, conde de Montemolín. Logró después huir a Génova y después a Trieste, donde falleció.

46 ARSEM, Libro de Actas de las Juntas de la Sociedad 110/38, Junta de Dirección de 30-7-1814.

47 ARSEM, Libro de Actas de las Juntas de la Sociedad 110/42, Junta de Dirección de 30-11-1816. Isabel, María Francisca y María Teresa (princesa de Beira) eran hijas de la infanta Carlota Joaquina y de Juan VI de Portugal. La infanta Carlota Joaquina era hija de Carlos IV y María Luisa de Parma, por tanto hermana de Fernando VII y del infante Don Carlos. María Teresa, la princesa de Beira, se casó con el infante Don Carlos cuando enviudó de su esposa Maria Francisca, hermana de la anterior. 
Dos años más tarde, el otro hermano de Fernando VII, el infante Francisco de Paula solicitó ser admitido en la matritense ${ }^{48}$. Llegó incluso a ser elegido director y al no aceptar el cargo se convirtió en protector ${ }^{49}$. Al contraer matrimonio con la infanta Luisa Carlota de Nápoles, ésta también pasó a formar parte como protectora de la Junta de Damas ${ }^{50}$. Dicha infanta era hermana de la que sería con el tiempo la cuarta esposa de Fernando VII, María Cristina de Nápoles ${ }^{51}$, madre de Isabel II y que fue la que autorizó, como Reina Gobernadora, a la muerte de su esposo y durante la minoría de edad de su hija, el restablecimiento de la institución en 1833.

Otros personas con vinculaciones indirectas con la familia real formaron parte de la entidad en este periodo. El parentesco aparece a través de la rama Borbón Vallabriga. Por un lado, Luis de Borbón y Vallabriga, arzobispo de Toledo, fue inscrito en $1802^{52}$. Era hijo del infante Luis, hermano de Carlos III y de su esposa, con la que había contraído matrimonio morganático, Teresa Vallabriga, condesa de Chinchón. Por otro, las hijas de este matrimonio estuvieron casadas con dos socios. Uno de ellos fue Manuel Godoy, el Príncipe de la Paz, favorito de Carlos IV, casado con María Teresa de Borbón y Vallabriga ${ }^{53}$. Godoy se incorporó en 1792 y alcanzó la dirección de la sociedad entre 1793 y 1797 y después en el año 1807. Otra hija, María Luisa, estaba casada con el duque de San Fernando y de Quiroga, Joaquín José Melgarejo Saurín, partícipe desde 1822, que fue ministro en el reinado de Fernando VII54. La enemistad de Fernando VII con Godoy, obligó al primero a rechazar la propuesta de enlace matrimonial con María Luisa para no convertirse en su cuñado.

48 (Aranjuez, 1794-Madrid, 1865). Su salida de Madrid en 1808 fue el motivo del inicio del 2 de mayo de 1808. Permaneció al lado de sus padres Carlos IV y María Luisa de Parma durante el exilio en Compiegne hasta 1812 y luego en Italia, en el periodo de la Guerra de la Independencia. Desde muy joven favoreció el desarrollo de las bellas artes y se dedicó al dibujo y la pintura con notable éxito, siendo elegido académico de honor y mérito de la de San Fernando. Desde 1838 a 1842 permaneció en Francia. Fue padre del rey Francisco de Asís, esposo de Isabel II.

49 ARSEM, Idem; Juntas de Dirección de 27-6-1818, 6-11-1818 y 27-5-1819.

50 ARSEM, Idem; Junta de Dirección de 7-8-1819.

51 Tanto Luisa Carlota como María Cristina eran hijas de la infanta María Isabel, esposa del rey Francisco I de Nápoles. Dicha infanta era hija de los reyes Carlos IV y María Luisa de Parma, por tanto hermana de Fernando VII y del infante Don Francisco de Paula.

${ }^{52}$ (Cadalso, Madrid, 1777-1823). En 1799 recibió el capelo cadrenalicio y la sede episcopal de Sevilla, siendo después trasladado a Toledo (1800). Durante la invasión francesa presidió la Regencia de Cádiz (1813) y sancionó el decreto que convocaba las Cortes Constituyentes. Con la llegada de Fernando VII a España fue desterrado a su diócesis, privándosele, sin embargo, de la administración y los bienes. En 1819 era Consejero de Estado y caballero del Toisón en 1820. Con la revolución de 1820 fue nombrado presidente de la Junta de Gobierno Provisional. Publicó en 1820 un Manifiesto titulado Españoles firmado por todos los miembros de la Junta.

53 (Castuera, Badajoz, 1767-París, 1851). Favorito del rey Carlos IV y de su esposa la reina María Luisa de Parma. En 1784 entró en los Guardias de Corps. En 1792 fue nombrado ministro de Estado. La guerra contra la república francesa que terminó con la Paz de Basilea le valió el título de Príncipe de la Paz. El descontento contra su excesivo poder provocó el motín de Aranjuez en 1808, que acabó con la abdicación de Carlos IV. Durante la Guerra de la Independencia permaneció al lado de los depuestos reyes, a los que acompañó después en el exilio en Roma. Tras la muerte de Carlos IV y Maria Luisa de Parma, ambos en 1819, se trasladó a París, donde vivió hasta su muerte, ya que nunca se le permitió volver a España.

54 Brigadier del ejército, recibió el título de Femando VII, que también le nombró Ministro de Hacienda en 1819 y después de Estado. En 1820 era consejero de Estado y en 1832 de la reina María Cristina. Fue director del la Real Sociedad Económica de Soria. Murió en Madrid en 1835. 
Otro parentesco, aunque ya no se trata de una vinculación con la familia real, sino con Godoy, es de Pedro Ceballos Guerra, casado con una prima segunda de Godoy ${ }^{55}$. Ceballos es un caso de supervivencia política adaptable a todo tipo de situaciones, siempre afín al poder político establecido. Finalmente, hay que citar otro caso de parentesco indirecto, aunque este se produjo bastantes años más tarde. José de Arredondo, conde de Vallellano y su hijo Manuel figuraron como afiliados. Esta familia tenía intereses en Cuba, donde residia el primero, por lo que se le hizo socio corresponsal en 1819. El hijo siguió la carrera militar, pues era miembro de la Guardia Real, se encontraba en Madrid cuando ingresó en la corporación en 1820. Un integrante de esta familia, Teresa de Arredondo, se casó con el infante Francisco de Paula en 1851, tras el fallecimiento de su primera esposa Luisa Carlota de Nápoles.

\subsection{Las familias de la nobleza}

Como ya se ha comentado anteriormente ha sido complicado identificar a los componentes de la aristocracia porque en las listas y las Juntas de la corporación suelen ser nombrados por sus títulos, con lo que se dificulta la labor, ya que había que tratar primero de conocer el verdadero nombre de la persona y cuando heredó su título, para pasar después a tratar de investigar las relaciones familiares que une a unos asociados con otros. Aun asi se han identificado varias sagas familiares.

Para empezar hay que citar a la familia del Conde de Floridablanca. José Moñino y Redondo, fue director entre 1789 y $1792^{56}$. Al morir en Sevilla en 1808 , cuando era presidente de la Junta Central, heredó su título su sobrina Vicenta Moñino y Pontejos (socia desde 1814) ${ }^{57}$, hija de Francisco Moñino y Redondo (hermano del anterior) y de Mariana de Pontejos y Sandoval, marquesa de Pontejos (socia desde 1787) ${ }^{58}$. Vicenta llegó a ser Presidenta de la Junta de Damas en 1860. Varios miembros de esta familia fueron incorporándose a la institución. Por

55 (1764-1840). En 1791 fue secretario de la embajada en Lisboa. Su parentesco con Godoy, le permitió ser consejero de Hacienda y en 1800 fue ministro con Carlos IV. Partidario de Fernando VII, después del motín de Aranjuez fue nombrado ministro de Estado. En Bayona firmó la Constitución y consiguió ser ministro del rey José. Tras Bailén abandonó a los franceses y perteneció a la Junta Central. Fue ministro de Estado durante la Regencia (1808). Fernando VII le nombró ministro de Estado en 1814 y de Gracia y Justicia en 1816. Posteriormente fue embajador en Nápoles (1816) y Viena (1819-1820). En 1820 se retiró de la política. También fue director de la Sociedad Económica de Soria y presidente de la Diputación en Madrid de la de Sevilla (1817-1819).

56 (Murcia, 1728-Sevilla, 1808) Estudió leyes en Orihuela y Granada. Ocupó los cargos de fiscal del Supremo Consejo (1766), embajador en Roma (1772). Una de las figuras más destacadas de la llustración, fue ministro de Estado con Carlos III, impulsando una política reformista de fomento de la industria, la marina y la instrucción pública. Destituido al iniciarse el reinado de Carlos IV, fue sometido a un proceso del que salió absuelto. Al inicio de la Guerra de la Independencia fue elegido Presidente de la Junta Central, muriendo mientras desempeñaba dicho cargo.

57 Nacida en 1795, fue dama de la reina Isabel II.

58 (Madrid, 1762-1834). Enviudó en 1808 del hermano del conde de Floridablanca, con quien había contraído matrimonio en 1786. Su tercer matrimonio con Joaquín Vizcaíno, la obligó a exiliarse en París en 1823, tras la caída del Trienio Liberal. 
un lado, Manuel Pando y Fernández de Pinedo, esposo de la condesa de Floridablanca (socio desde 1819), marqués de Miraflores ${ }^{59}$. Por otro, Joaquín Vizcaíno, tercer esposo de Mariana Pontejos y Sandoval, que fue director en 1839 y que fue conocido por el título de marqués de Pontejos ${ }^{60}$.

Otra de las familias es la del Duque de Híjar. Agustín Pedro de Silva y Palafox, integrante desde 1800, director en 1808 y posteriormente, tras la Guerra de la Independencia, desde 1814 hasta 1817 , en que falleció6 ${ }^{61}$. Su padre, Pedro $\mathrm{Pa}$ blo de Silva y Abarca de Bolea, fallecido en 1808, también Duque de Híjar, había sido socio y también su hermana mayor María Pilar Silva y Palafox ${ }^{62}$, socia desde 1799 y presidenta de la Junta de Damas desde 1826 a 1828, casada en primeras nupcias con Pedro Abarca de Bolea, conde de Aranda (hermano de su abuela paterna Engracia Abarca de Bolea) y en segundas con el duque de Alagón, Francisco Fernández de Córdoba y Glymes de Brabante, aceptado en $1818^{63}$.

La familia del duque de Hijar está vinculada a otros socios. Por un lado, la madre de Agustín Pedro y María Pilar, fue Rafaela Palafox Croy D'Habré, hermana de Felipe Palafox Croy D'Habré, marido de la condesa de Montijo, María Francisca de Sales Portocarrero, una de las fundadoras de la Junta de Damas ${ }^{64}$. Una de las hijas de este matrimonio María Tomasa Palafox y Portocarrero, marquesa de Villafranca, por tanto prima de los primeros, era socia desde 1799 y fue presidenta de la Junta de Damas entre 1817 y1824${ }^{65}$. María Tomasa estaba casada con Francisco Alvarez de Toledo y Gonzaga (marques de Villafranca y duque de Medina-

59 (Madrid, 1792-Madrid, 1872). Desde muy joven intervino en la política y militó en el partido moderado. En 1834 fue embajador de España en Londres y en París (1838-1840). Fue nombrado intendente de la Real Casa y Patrimonio en 1848, presidente del Senado en varias legislaturas y del Consejo de Ministros en 1865. Perteneció a la Academia de la Historia, contribuyó a la terminación de la Guerra Carlista y se distinguió como orador. Fue un escritor fecundo de gran número de obras históricas, referidas principalmente al reinado de Isabel II.

60 (La Coruña, 1790-Madrid, 1840). De ideas liberales, tuvo que emigrar junto a su esposa a Francia tras la caída del régimen constitucional. Al volver a España, se dedicó a las obras sociales. Fue uno de los fundadores del Ateneo y la Caja de Ahorros. Fue además corregidor de Madrid, contribuyendo a la mejora urbana de la ciudad.

61 (1773-Madrid, 1817). Grande de España y gentilhombre de S.M. Fue miembro de la Real Academia Española. Formó parte del Consejo de Estado y del de las Ordenes. Escribió las tragedias Las tro. yanas y Los celtiberos. Fue director de la Sociedad varias veces y trabajó incansablemente por su desarrollo, con lo que contribuyó a mantener el prestigio de la Sociedad. Autor de numerosas memorias, discursos e informes para la institución.

62 Condesa de Castelflorido. Fue camarera mayor de la reina María Cristina. Murió en 1835.

63 (Zaragoza, 1758-Madrid, 1841). Hijo del Conde de Sástago, era barón de Espes y Alfajarín. Fue destinado a la Iglesia, llegando a ser abad de Lodosa, pero prefirió dedicarse a la carrera militar. Con veinte años ingresó en la Guardia Real. En 1802 era teniente general. Durante la Guerra de la Independencia, la Junta Central le ofreció el Virreinato de Méjico, pero rehusó. En 1814 era comandante de las Guardias de Corps. En 1815 recibió la Grandeza de España y llegó a capitán general.

64 Esta mujer destacó en su época como ilustrada, llegando a ser denunciada ante la Inquisición por jansenista, aunque fue absueita. Uno de sus hijos, que heredó el título de conde de Montijo, figuró en muchos de los sucesos políticos del primer tercio del siglo XIX, ya que tuvo gran habilidad para la intriga.

${ }^{65}$ (Madrid, 1780-Portici, Italia, 1835). Académica de mérito en la Academia de San Femando. Era aficionada a la pintura. 
sidonia) ${ }^{66}$. Una de las hermanas del marqués de Villafranca, María Ignacia Alvarez de Toledo y Gonzaga estaba casada con el conde de Altamira, Vicente Osorio de Moscoso y Guzmán, inscrito en $1776^{67}$.

Los lazos de parentesco que se han averiguado de esta familia acaban aquí, pero está claro de que la repetición de apellidos como Silva, Palafox y Portocarrero intuye más relaciones con otros afiliados. Sería el caso de Vicente María Cañas Portocarrero, duque del Parque (partícipe desde 1775), que fue director de la institución en los años 1819 y $1820^{68}$. También Pedro María de Urries y Pignatelli (incorporado en 1787$)^{69}$, que estuvo casado en primeras nupcias con María Nicolasa Palafox ${ }^{70}$.

Otras ramas colaterales con ramificaciones familiares aparecen con los apellidos Gonzaga y Pignatelli. Respecto a los Gonzaga, la madre del marqués de ViIlafranca, María Antonia Gonzaga y Caracciolo era hermana de María Micaela, que casó con el VI Duque de Abrantes, abuelo del poseedor del titulo del que se hablará posteriormente. Otra de las hermanas, María Francisca casó con el XII duque de Medinaceli, cuyo hijo, el XIII duque, Luis María Fernández de Córdoba y Gonzaga $^{71}$, perteneció a la corporación hasta su muerte en 1806, al igual que el nieto Luis Joaquín Fernández de Córdoba y Benavides (socio desde 1800) ${ }^{72}$. Una her-

${ }^{66}$ Francisco Alvarez de Toledo heredó los títulos a la muerte de su hermano José en 1796, que fue esposo de la duquesa de Alba, María Pilar Cayetana de Silva y Alvarez de Toledo, fallecida en 1802. Esta duquesa es la de los cuadros de Goya. Estuvo implicado en los sucesos de marzo de 1808 conocidos como motín de Aranjuez. Después del 2 de mayo participó activamente en la lucha contra los ejércitos napoleónicos al tiempo que desempeñó la representación de Murcia en las Cortes de Cádiz. Falleció en 1821, durante el Trienio Liberal.

67 Alférez mayor de Castilla y de la villa de Madrid. Formó parte de la Junta Central durante la Guerra de la Independencia. Murió en 1816.

68 (Valladolid, 1755-Cádiz, 1824). General español y Grande de España. Era teniente general en 1798. Gozó del favor de Carlos IV y fue uno de los que le aconsejaron que fuese a Bayona para conferenciar con Napoleón. Una vez allí, viendo como se desarrollaban los acontecimientos, regresó a España y se ofreció a la Junta Central, que le encargó el mando del ejército de Castilla. Derrotó a los franceses en las cercanías de Medina del Campo, pero no fue tan afortunado en Alba de Tormes ni en la recuperación de la plaza de Tarragona. En 1810 perdió la contianza de la Junta y fue enviado a Tenerife. En 1816 fue nombrado por Fernando VII embajador de España en París. Defendió la revolución de 1820 y fue presidente de las Cortes. Murió en la cárcel, donde había sido encarcelado por orden de Fermando VII tras la restauración del absolutismo.

69 Entró muy joven a servir al entonces Príncipe de Asturias, luego Fernando VII, al que acompañó a Valençay, donde prestó grandes servicios por lo que fue separado de la servidumbre del monarca. Fue encargado de realizar una comisión en Valençay por la Regencia de Cádiz y al volver a España fue asesinado en Navarra (1810).

70 María Nicolasa Palafox era hija de los marqueses de Ariza, emparentados con la familia de la condesa de Montijo, ya citada y con la familia del marqués de Lazán. Uno de los hijos del marqués de Lazán, Luis Rebolledo de Palafox y Melci, que heredó el título, estaba casado con María Gabriela Palafox y Portocarrero, otra hija de la condesa de Montijo. Otro de los hijos, José Rebolledo de Palafox y Melci, fue el capitán general de Zaragoza cuando los sitios de Zaragoza en la Guerra de la Independencia.

71 (1749-1806). Estuvo casado desde 1764 con Joaquina Benavides y Pacheco, duquesa de Santiesteban del Puerto.

72 (1780-1840). Fue director de la Sociedad Económica de Lucena entre 1817 y 1833 . Formó parte del Consejo de Gobierno de la reina María Cristina en 1833. Se casó en 1802 con María de la Concepción Ponce de León y Carvajal, hija de los IV duques de Montemar. Una hermana de su esposa, María del Carmen Ponce de León y Carvajal contrajo matrimonio con Vicente Osorio de Moscoso y Alvarez de Toledo, hijo del Conde de Altamira. 
mana de XIII duque, María Soledad, contrajo matrimonio con el VII duque de Abrantes, de cuyo hijo se hablará posteriormente. En cuanto a los Pignatelli, las relaciones se concretan en la persona del duque de Villahermosa, José Antonio Azlor de Aragón y Pignatelli (integrante desde 1818) ${ }^{73}$, hijo de Juan Pablo Azlor de Aragón y Urries y María Manuela Pignatelli de Aragón y Gonzaga ${ }^{74}$.

Pasemos a la casa de Osuna. El duque de Osuna, Pedro de Alcántara Téllez-Girón y Pacheco (inscrito en 1783) fue director de la sociedad en los años 1786 a 1788 y en $1805^{75}$. Bajo su mandato se creó la Junta de Damas de la que fue primera presidenta en 1787 su esposa la duquesa de Benavente, Josefa Alfonso Pimentel Téllez-Girón (partícipe desde 1786) ${ }^{76}$. Su hija Joaquina Téllez-Girón ${ }^{77}$, marquesa de Santa Cruz, casada con José Joaquín Silva Sarmiento, marqués de Santa Cruz, era socia desde 1806; otra de sus hijas, Josefa Manuela (incorporada en 1814), estaba casada con Angel María Carvajal y Fernández de Córdoba, VIII duque de Abrantes (afiliado en el mismo año) y también fue socia su nuera la duquesa de Osuna, María Francisca Beaufort, esposa de su hijo Francisco de Borja Téllez-Girón y Pimente ${ }^{78}$. Como se ha dicho anteriormente, el duque de Abrantes estaba emparentado con los Gonzaga y los Medinaceli, pero también con el duque de Granada de Ega, Francisco Javier Idiaquez y Carvajal (asociado desde 1787) ${ }^{79}$, ya que la madre de éste era hermana del VI Duque de Abrantes.

También cuenta con varios socios entre sus familiares el duque de Noblejas, Mariano del Amparo Chaves y Villarroel (miembro desde 1799), presidente de la entidad entre 1821 y $1822^{80}$. Su hermano Ramón de Chaves y Villarroel que ingresó en 1814. Dos de las tres esposas que tuvo también figuraron como socias en el periodo analizado, la segunda Concepción Auñón ${ }^{81}$, marquesa de San Bartolomé del Monte (socia desde 1807) y la tercera, Joaquina de Loaisa y Topete (socia desde 1820).

\footnotetext{
73 Muerto en 1852.

74 María Manuela Pignatelli de Aragón y Gonzaga (1753-1816) era hija de María Luisa Gonzaga Caracciolo, hermana de las citadas anteriormente María Antonia, María Micaela y María Francisca.

75 (Madrid, 1755-1807). Teniente general del Ejército, coronel de las Guardias Españolas. Fue miembro del Consejo de Guerra, gentilhombre de S.M. y embajador en Viena. Perteneció a la Real Academia Española. En el reinado de Carlos IV iniciada la guerra contra la Francia revolucionaria, tomó parte en ella en 1794, durante la cual derrotó a los franceses a orillas del río Deva y en Roncesvalles al general Moncey. Fue director de la Sociedad Económica de Benavente.

76 (Madrid, 1752-1834). Contrajo matrimonio con el duque de Osuna en 1774. Este matrimonio fue aficionado a las artes y protegió a Goya.

$\pi$ Nació en 1884.

78 Casado en 1802. Murió en 1820.

79 Teniente general de los Reales Ejércitos y capitán de los Guardias de Corps.

${ }^{80}$ Grande de España, obtuvo el título de duque en 1820. En 1814 fue encarcelado junto a su hermano por Fernando VII, al haberse distinguido los dos hermanos por sus ideas liberales. Formó parte del Ayuntamiento de Madrid en los años 1820 y 1821. En 1825 fue sometido a proceso para su purificación. Poseía la Gran Cruz de Carlos III. Formó parte del Estamento de Próceres (1834) y fue miembro de la Real Academia de San Fernando.

${ }^{81}$ En la lista de 1818 ya no figura.
} 
Respecto a Francisco Cabarrús ${ }^{82}$, conde de Cabarrús, partícipe desde 1776 hasta su muerte en 1810 y su hijo Domingo, sucesor en el título y también afrancesado, ingresó en la institución en 1811. Otra familia es la del marqués de Cerralbo. Fernando Aguilera y Contreras fue incorporado en 1818 y fue director en 1833, en la primera etapa del restablecimiento de la corporación tras la muerte de Fernando $\mathrm{VII}^{83}$. Su madre María Josefa Contreras y Vargas, ya lo era desde antes de 1806 y en 1820 se hizo socia su esposa María Magdalena Fernández de Córdoba.

Además, se pueden establecer vínculos de parentesco en la familia del duque de Frías. Diego Fernández de Velasco ingresó en $1787^{84}$, su esposa Francisca de Paula Fernández de Velasco en 1811, y su nuera María Piedad Roca de Togores en $1817^{85}$, casada con el hijo de los anteriores Bernardino Fernández de Velasco. Respecto al primero, cuyos verdaderos apellidos eran López Pacheco, estaba emparentado con su propia esposa, con los Osuna y con la casa de Alba. La trayectoria política de esta familia no deja de tener interés, ya que mientras el padre se puso al lado de los franceses en la Guerra de la Independencia, el hijo abrazó el bando contrario y combatió en el ejército español. Además, por sus ideas liberales, favorables a la continuación del régimen constitucional en 1814 , se vio obligado a emigrar a Inglaterra entre 1814 y 1820 para evitar ser encarcelado, como les había ocurrido a otros muchos que simpatizaban con las mismas ideas.

${ }^{82}$ (Bayona, Francia, 1752-Sevilla, 1810). Era hijo de un comerciante de Bayona y muy joven pasó a Zaragoza, donde se casó con la hija de su principal Galabert, estableciendo después una fabrica de jabón en Carabanchel. Empezó a dedicarse a los estudios económicos, entablando amistad con el conde de Floridablanca que vio en él aptitudes para la Hacienda, llegando a ser consejero de Estado con Carlos III. Su proyecto de emisión de vales reales que fue aplicado con notable éxito, consolidó su fama. En 1782 se le confió la dirección del Banco de San Carlos, proyecto suyo y tres años más tarde contribuyó a fundar la Compañía del comercio de Filipinas y fue nombrado individuo del consejo Real de Hacienda. Acusado por el gobierno de Carlos IV de malversación de fondos públicos, fue encarcelado durante dos años. Finalmente fue declarada su inocencia en juicio. Con la llegada a España de José Bonaparte, fue nombrado ministro de Hacienda, cargo que conservó hasta su muerte, pero en el que no pudo desplegar sus dotes de hacendista por las excepcionales circunstancias que atravesaba el país.

${ }_{83}$ Grande de España, era coronel de Caballería. Recibió la Gran Cruz de Carios III en 1819. Formó parte de la Junta de Gobierno del Banco de San Carlos en 1819-1820. En el Trienio Liberal fue nombrado Jefe político de Madrid (1820-1821) y durante su mandato cerró la Fontana de Oro en 1820. Entre 1822 y 1823 fue consejero de Estado. Además perteneció a la Real Junta de Ganaderos y al Estamento de Próceres en 1834. Durante su mandato como director contribuyó al desarrollo activo de la Sociedad. En 1838 recibió al Toisón de Oro y poco después murió.

${ }^{84}$ (Madrid, 1754-París, 1811). Militar y diplomático español. Grande de España. Sumiller de guardias de Corps. En 1793 ascendió al grado de coronel del regimiento de infantería de León, como recompensa de haber formado dicho regimiento a su costa, luego se le nombró brigadier y mariscal de campo, y tomó parte en la guerra contra Francia hasta la paz de Basilea. Desde 1798 a 1801 fue embajador extraordinario y plenipotenciario de España en Portugal y en 1802 se le nombró embajador de España en Londres, cargo que no liegó a ocupar, ascendiendo poco después a teniente general. Además fue consejero de Estado. Al subir al trono Fernando VIl en 1808, le delegó, junto con otros grandes de España, para salir al encuentro de Napoleón cuando éste se dirigió a España. Con José Bonaparte fue nombrado embajador en Francia, donde se encontraba cuando murió.

${ }_{85} \mathrm{Hija}$ de los condes de Pinohermoso. 
Se han localizado otros matrimonios, por ejemplo el duque de Fuerte Hijar, Germano de Salcedo y Somodevilla (socio desde 1793$)^{86}$, que fue director en 1802 y 1803 y su esposa, María Lorenza de los Ríos (socia desde 1788) y presidenta de la Junta de Damas en $1811^{87}$. El primero fue una víctima de la guerra y durante la invasión napoleónica fue llevado preso a Francia por no querer adherirse a la causa francesa. Al poco tiempo falleció en Bayona. Otro matrimonio de asociados es el del marqués de Portago, Francisco de Paula Terán (integrante desde 1800 ) y su esposa, que ingresó a la vez que su marido. El marqués de Portago estuvo al frente del ejército español en la Guerra de la Independencia. También el conde de Casa-Sarriá, Joaquín Navarro Sangran y su esposa, los dos en $1818^{88}$. También el marqués de Almenara, José Martínez de Hervás (inscrito en 1794), que fue director durante la invasión francesa y ministro del Interior en el gobierno de José Bonaparte ${ }^{89}$. El socio Luis Martínez de Hervás, que debia ser familiar, quizá hermano o hijo, fue admitido en 1811 y también afrancesado.

Finalmente, aparece como afiliado en 1775 Francisco Rodríguez Campomanes, hermano del conde de Campomanes, Pedro Rodríguez Campomanes, el fiscal del Consejo de Castilla que promovió la fundación de las sociedades económicas y que fue uno de los primeros socios, aunque como falleció en 1803 no figura en las listas consultadas. Por otro lado, el heredero del título de conde, Gabino Campomanes, también perteneció a la corporación ${ }^{90}$.

\subsection{Relaciones de parentesco entre el resto de socios}

Después de lo relatado en el apartado anterior, parece que la Sociedad Matritense estaba copada por la aristocracia española, pero no era así. Si bien en el caso de las socias femeninas hay una gran mayoría que poseen título, un $80 \%$, en cambio, en el caso de los masculinos, es aproximadamente del $10 \%$, incluyendo a los componentes de la familia real. La razón hay que buscarla en el propio objetivo al crearse la Junta de Damas, ya que solo las esposas o hermanas de miembros

86 (Santo Domingo de la Calzada, 1748-Bayona, 1809). Era sobrino del marqués de la Ensenada. Fue oidor de la Chancillería de Valladolid y primer director de la Sociedad Económica de dicha ciudad en 1789. Durante su mandato como director de la Sociedad Económica de Madrid se fundaron la Escuela de Sordomudos y la de Taquigrafía.

${ }_{87}$ Aficionada a las letras, fue protectora de artistas y literatos. Además se le atribuye la autoría de dos comedias El engreido y La sabia.

(Valencia, 1769-Madrid, 1844). Militar español. Comenzó como cadete en el Colegio de Artillería de Segovia y fue promovido a subteniente de dicha arma en 1786. Tomó parte en la campaña contra la República francesa de 1793 a 1795, en la Guerra de Portugal de 1801 y en toda la Guerra de la Independencia, desde la batalla de Bailén. Ascendió a teniente general en 1815. En 1820, elegido capitán general de Granada, no quiso aceptar el cargo, renunciando también a los cargos de secretario de Estado y del Despacho Universal de la Guerra que le fueron ofrecidos. Sus trabajos sobre artillería fueron notables y alcanzaron gran renombre en su época.

89 Perteneció al Supremo Consejo de Hacienda en tiempos de Carlos IV. Destacado afrancesado, fue ministro del Interior con José Bonaparte.

90 No se ha podido establecer el parentesco entre Pedro Rodriguez de Campomanes y Gabino Campomanes. Podría tratarse de un hijo o un sobrino. 
de la nobleza o de altos funcionarios civiles o militares tenían tiempo para dedicarse a la supervisión de labores de educación y beneficencia que les estaban confiadas. Las mujeres de la burguesía, normalmente, estaban dedicadas a la casa y los hijos, aparte de quizá la educación recibida, las costumbres sociales e incluso el nivel económico, les impedía acceder a la institución. Solo se ha encontrado un caso, en lo que se ha podido investigar hasta este momento, de matrimonio no perteneciente a la aristocracia en el que los dos eran socios. Se trata de Joaquín María Sotelo (inscrito en 1797) ${ }^{91}$, fiscal del Consejo de Castilla y posteriormente afrancesado, y María de las Mercedes Porres de Sotelo (partícipe desde 1807).

En los socios masculinos se observan varios casos de posible parentesco, aunque en algunos de ellos, a pesar de la coincidencia de apellidos, salvo que por la documentación analizada se revele la filiación, no es posible saber más. Uno de los casos más claros es el de los hermanos Claudio y Esteban Boutelou, botánicos, que se incorporaron en 1800, los dos profesores del Jardín Botánico. Claudio ocupó varios puestos directivos, habiendo sido subdirector en 1811 y luego director en $1813^{92}$. Esteban fue nombrado bibliotecario en 1813 , pero poco después murió ${ }^{93}$. El primero cayó en desgracia en 1814 por haber aceptado el gobierno de José Bonaparte, por ello tuvo que someterse a un proceso de purificación y a vivir alejado de Madrid.

También hay parentesco entre José Mariano Vallejo ${ }^{94}$, y Andrés Vallejo. Estos dos hermanos se asociaron sucesivamente, el primero en 1815 y el segundo un

91 Fue prefecto de Jerez de la Frontera en 1811. Tras la retirada francesa estuvo encarcelado en Zaragoza, donde permanecia en 1816. En 1821, ya libre, fue miembro de la Audiencia de Sevilla, cargo en el que permanecía en 1826.

${ }_{92}$ (Aranjuez, 1774-Sevilla, 1842). Agrónomo y naturalista español. Desde 1790 a 1798 permaneció en Inglaterra y Francia con pensión real, en compañía de su hermano Esteban, para estudiar botánica, agricultura y horticultura. Fue profesor de Botánica y de Agricultura y Economía rural en el Real Jardín Botánico, del que fue Jardinero Mayor. Obtuvo el puesto de director del Jardín Botánico de Madrid, que le fue confirmado por el gobierno de José Bonaparte, durante cuyo reinado logró evitar la destrucción de dicho Jardín que los franceses querian arrasar para destinar su emplazamiento a obras de fortificación. Al regresar a España Fernando VII, fue depuesto de sus cargos, hasta que se le destinó de catedrático de agricultura primero a Alicante y después a Sevilla. Fue redactor del Semanario de Agricultura de Madrid, publicando numerosos artículos, muchos de ellos en colaboración con su hermano.

${ }_{93}$ (Aranjuez, 1776-San Lucar de Barrameda, Cádiz, 1813) Pasó a estudiar al extranjero y fue profesor del Jardín Botánico de Madrid. Publicó numerosos artículos en el Semanario de Agricultura y en los Anales de Ciencias Naturales de Madrid. Colaboró con su hermano en el Tratado de la huerta (1801) y en el Tratado de las flores (1804).

${ }_{94}$ (Albuñuelas, Granada, 1779-Madrid, 1846). Comenzó sus estudios en la Universidad de Granada, donde se interesó por las matemáticas. En 1801 fue propuesto para desempeñar el cargo de sustituto de cátedras en la sección de matemáticas de la Real Academia de San Fernando. Ese mismo año también fue encargado de enseñar geometría práctica. En 1802 obtuvo la cátedra de matemáticas, fortificación, ataque y defensa de plazas del Seminario de Nobles. Durante la Guerra de la Independencia trabajó en el laboratorio de fuegos artificiales del cuerpo de Artillería. En 1818, por encargo del alcalde corregidor de Madrid, llevó a cabo los trabajos de nivelación de los ríos Jarama, Lozoya y otros. En 1823 tuvo que emigrar tras la caída del régimen constitucional y se dedicó al estudio de los principales sistemas pedagógicos de Europa y a la enseñanza en París. En 1832, tras su regreso a España todos sus esfuerzos se dirigieron a mejorar los métodos de instrucción primaria. Gracias a sus iniciativas se crearon dos escuelas normales en Madríd, ampliándose además sus programas de estudios. Fue diputado y senador, director del gabinete geográfico, oficial mayor del ministerio de la Gobernación, jefe de la sección de Caminos y Canales, inspector de Instrucción Pública y director general de estudios. Contribuyó a la fundación del Ateneo de Madrid y de la Real Academia de Ciencias Naturales. 
año después. Respecto al primero hay que destacar que se trata de un pedagogo y matemático importante de la primera mitad del siglo xix y el segundo era militar, aunque también dedicado a la enseñanza como profesor de matemáticas y fortificaciones en el Real Colegio Militar de Gandía. La biografía de José Mariano Vallejo es muy parecida a la de otros miembros de la corporación. Educados en la llustración, fueron el primer fruto de los esfuerzos reformistas del reinado de Carlos III, pero la Guerra de la Independencia y los sucesos posteriores les obligan a definirse políticamente. Unos, optaron por someterse al gobierno francés, como ya se ha visto anteriormente, $y$ otros como Vallejo fueron afines al Liberalismo y obligados a emigrar en 1823.

Además, pueden servir como ejemplo de otras actitudes políticas los hermanos Manuel María Arjona y Cubas $^{95}$, y José Manuel Arjona y Cubas ${ }^{96}$, que ingresaron los dos en 1818. Manuel María pertenecía al clero que colaboró con los franceses en la Guerra de la Independencia, por lo que fue perseguido. Además destacó como poeta. En la Sociedad Matritense fue encargado en 1818 de la cátedra de Economía Política. Su hermano José Manuel, en cambio, fue un destacado absolutista, que persiguió a los liberales durante los diez últimos años del reinado de Fernando VII.

A continuación se citarán otros lazos encontrados, menos conocidos que los anteriores. Por ejemplo, los hermanos Francisco Izquierdo y José Segundo Izquierdo: el primero era miembro desde 1817 y el segundo en 1820, que al solicitar su admisión comunicó su vinculación familiar. El primero fue un asociado laborioso para la institución, que ocupó el cargo de tesorero en 1821. Un año después lo desempeñaría su hermano, quien abrazó la profesión militar, con el grado de teniente coronel en 1820 y era integrante de la Junta de Sanidad.

Otro caso de vinculación familiar es la de los hermanos apellidados Villanova y Jordán, de nombres José y Vicente. El primero fue inscrito en 1810, aunque no debió ser afrancesado, ya que en 1816 era oficial de la Secretaría del Real Patrimo-

95 (Osuna, Sevilla, 1771-Madrid, 1820). Estudió filosofía en la universidad de Osuna y se doctoró en derecho en la Universidad de Sevilla. Fundó la Academia Letras Humanas en 1793 y fue uno de los representantes de la escuela sevillana en unión de Lista, Reinoso, Blanco, etc. Fue colegial mayor de Santa María de Jesús en Sevilla, del que años después sería rector. A los veinte años alcanzó el puesto de doctoral de la real capilla de San Fernando, en la misma ciudad. Fue también canónigo penitenciario de la Catedral de Córdoba (1801). Durante la Guerra de la Independencia escribió una Memoria sobre el modo de celebrar Cortes en España que envió a la Junta Central. Con la entrada de los franceses en Córdoba, tuvo que colaborar con ellos en 1810. Fundó allí la Academia de Ciencias, Bellas Letras y Nobles Artes de Córdoba y desarrolló la sección literaria de la Sociedad Económica de dicha ciudad. Dirigió por encargo de Mariano Luis Urquijo y Pedro Estala el periódico de Córdoba Correo político y militar. En 1812 abandona Córdoba y se dirige a Cádiz, pero es detenido en Ecija acusado de afrancesado. En 1814 publicó un Manifiesto de autojustificación. En 1818, en Madrid, fue consejero de Fernando VIl y secretario de la Academia Latina, pero en 1819 fue desterrado, trasladándose a Córdoba. Tras el pronunciamiento de Riego en 1820 escribió una memoria titulada Necesidades de la España que deben remediarse en las próximas Cortes, publicada en Córdoba por la Asociación de Bien Público. Encontrándose en Madrid le sorprendió la muerte. Se dedicó a la poesía sagrada, siendo muy notables sus composiciones.

${ }_{96}$ Ministro togado de la Audiencia de Extremadura en 1807. Fue corregidor de Madrid y miembro de la Cámara de Guerra en 1819. Además perteneció a la Real Junta de Caridad y Presidente en Madrid de la Real Sociedad de Córdoba (1819-1829). En 1824 ocupó el cargo de superintendente de policía. 
nio y para la matritense desarrolló las labores de censor en 1813 , secretario en 1816, archivero en 1816 y tesorero en 1817. Después cedió el testigo a su hermano Vicente, que se hizo socio en 1817 , que pertenecía al clero y fue uno de los pocos afiliados que con su trabajo consiguió que la entidad no desapareciese en los diez años que van desde 1823 a 1833. Durante prácticamente todo el periodo desempeñó el cargo de secretario de la corporación, para el cual habia sido elegido en las últimas elecciones realizadas en 1822.

También José y Juan Acevedo y Salazar, el primero José se incorporó en 1805 , tenía la profesión de abogado. El otro, Juan, admitido en 1815 , fue secretario de la sociedad en 1816 y 1820 y tesorero en $1817^{97}$. Este último presenta ciertos aspectos oscuros en lo poco que se conoce de su biografía, pues en las Juntas de Dirección se hace varias veces alusión a salidas precipitadas de Madrid en los años 1816 y 1817, con motivo de viajes a Sevilla y Cádiz, de los que se tiene conocimiento por la obligación de informar a la Junta por desempeñar cargos de responsabilidad. Por último, habría que destacar el caso de dos hermanas, socias de la Junta de Damas. Se trata de Francisca Cepeda y Rosario Cepeda, ésta última secretaria de la Junta de Honor y Mérito entre 1807 y $1813^{98}$.

Hay otros casos de coincidencia de apellidos, que hacen intuir su relación de parentesco, pero que a lo largo de la investigación no se ha podido averiguar. Por ejemplo, podemos citar en primer lugar a José Vinuesa López de Alfaro (inscrito en 1811) ${ }^{99}$, y Matías Vinuesa López de Alfaro (partícipe desde 1815) ${ }^{100}$. Dos personas de trayectorias políticas totalmente distintas. El primero afrancesado, ocupaba el empleo de oficial de la secretaría del Consejo de Estado cuando ingresó en la entidad. El segundo fue guerrillero durante la guerra y en el Trienio liberal conspiró contra el régimen constitucional. De todas maneras, respecto a éste último, no se trató de un miembro muy activo y en 1819 figura como moroso por no haber pagado la cuota y posteriormente fue borrado de la corporación. En realidad, no se trataba de una institución muy acorde con sus ideas.

97 Desde 1817 a 1820 fue Vocal de la Junta de la Compañía de Filipinas. En 1819 y 1820 aparece como vicepresidente de la Diputación de Madrid de la Real Sociedad Económica de Cádiz. Pertenecía a la Junta de Caridad (1818-1820). Actuó como comisionado de las Cortes en el empréstito Arnoid-Hubbard en 1821. Exiliado en Londres en 1823, posteriormente en octubre de 1827 se encontraba en Bayona, siendo vigilado por la policía francesa.

${ }_{98}$ Era la madre del político y literato Eduardo Gorostiza y Cepeda, de ideas liberales que, tras la caida del régimen constitucional en 1823, abandonó España y viajó a Méjico, de donde era oriundo, ofreciéndose a las autoridades independentistas de aquel país.

99 Se exilió en Burdeos tras la retirada francesa en 1814. En 1830 se encontraba en España como oficial de la Secretaría de Gracia y Justicia.

100 Sacerdote y guerrillero español, conocido como el cura de Tamajón. Al iniciarse la Guerra de la Independencia era sacerdote en dicho pueblo y organizó una partida guerrillera contra los franceses. Defendió el régimen absolutista desde el púlpito y la imprenta. Fue agraciado con un arcedianato en Tarragona y con el nombramiento de capellán honorario del Rey. En 1820 organizó una conspiración para derribar al gobierno constitucional, pero sorprendido por las autoridades fue encerrado en la cárcel. Después del proceso, en el que se comenzó solicitando la pena de muerte, fue condenado a diez años de presidio. Esto causó gran indignación y unos alborotadores asaltaron la cárcel, asesinándole en 1821. En 1823 , después del restablecimiento del régimen absoluto, algunos de sus asesinos fueron ejecutados. Escribió folletos de carácter político. 
Los asociados Joaquín Ventura de Romaña (afiliado desde 1778) y Domingo de Romaña (socio desde 1790), podrían ser también parientes. Al igual que dos que coinciden en el apellido Abarrategui: Santiago (incorporado en 1801) ${ }^{101}$, y el segundo, Juan Agustín, que ingresó dos años después ${ }^{102}$. También Santiago Grimaud (partícipe desde 1800) y Francisco Grimaud de Velaunde (desde 1816), quizá era su hijo. Esta persona fue bastante activa y participativa. Por ejemplo, durante un viaje que realizó a Francia en 1819 se encargó de visitar varias instituciones científicas y culturales francesas. También compró libros y periódicos que envió a Madrid en los que se explicaban descubrimientos e inventos que pudieran ser provechosos para el progreso científico y económico de España.

También hay dos asociados de apellido Fernández de Navarrete, Antonio y Martín ${ }^{103}$, el primero socio desde 1781 y el segundo desde 1791. Puede ser que se trate de hermanos, o padre e hijo, ya que el padre del segundo se llamaba José Antonio. El primero es un importante marino y escritor de la primera mitad del siglo $\mathrm{XIX}$, como se puede ver por su biografía y un ejemplo de cómo también en aquellos años se podia vivir alejado de la política.

101 Comisario ordenador de Ejército honorario desde 1800 a 1823.

102 Magistrado de la Chancillería de Granada de 1815 a 1820.

103 (Abalos, La Rioja, 1765-Madrid, 1844). Estudió en su pueblo natal, en Calahorra y en el Real Seminario de Vergara, siendo admitido en 1780 como guardiamarina, en el departamento del Ferrol, embarcando en el navío San Pablo en 1781 bajo la dirección de José de Mazarredo. Con motivo de la muerte del conde de Peñaflorida, fundador y director de la Real Sociedad Vascongada, en 1784 compuso el Elogio póstumo y publicó en el periódico El censor de Madrid, algunos artículos sobre las reformas en ciertas órdenes militares y sobre el teatro. En 1786 fue destinado a Cartagena, donde se dedicó al estudio de las matemáticas, navegación, maniobra y arquitectura naval, bajo la dirección de Gabriel Ciscar, completando así su educación científica. Declarada la guerra a la República Francesa en 1793, volvió al servicio activo y ascendió a capitán de fragata. Regresó a Cartagena, participando en las expediciones contra Francia y contra Inglaterra. Al ser nombrado Juan de Lángara ministro de Marina(1799), le llevó de oficial de la secretaría de Despacho de Marina. Se dedicó entonces al establecimiento del Depósito Hidrográfico, proyecto en el que tuvo éxito. En 1799 fue confirmado en el empleo de capitán de navío y un año más tarde la Academia de la Historia le nombró individuo supernumerario. En 1803 fue ascendido a oficial mayor de la secretaría de Marina, puesto en el que permaneció hasta 1807 en que fue nombrado ministro contador fiscal en el Tribunal Supremo del Almirantazgo. A inicio de la Guerra de la Independencia, Napoleón le nombró consejero de Estado e intendente de marina, cargo que no aceptó, retirándose a la vida privada. En mayo de 1815 fue nombrado secretario de la Academia de San Fernando, puesto que compagina desde $1816 \mathrm{con}$ el de Bibliotecario de la Real Academia Española y secretario de la Diputación de Madrid de la Sociedad Económica Riojana. En 1819 la Academia española publicó su trabajo sobre la vida de Cervantes. Durante el Trienio Liberal, las Cortes le nombraron miembro de la Comisión de Marina y de la de Instrucción Pública. En 1822 forma parte de la Academia Nacional, sección de Ciencias Físico-Matemáticas. En 1823 se le ofreció la dirección de Depósito Hidrográfico, que ocupó interinamente y en 1825 fue nombrado vocal de la Junta de dirección de la Real Armada, y director de la Academia de la Historia, cargo que ocupó hasta su muerte, siendo reelegido sucesivamente. En este periodo comenzó la publicación de su obra más importante: Colección de los viajes y descubrimientos que hicieron por mar los españoles desde fines del siglo XV, con varios documentos inéditos convenientes á la historia de la marina castellana y de los establecimientos españoles en Indias (1825-1837). En 1834 fue nombrado consejero decano de la sección de marina del Consejo Real de España e Indias y prócer del reino y posteriormente fue senador en todas las legislaturas hasta su muerte por su provincia de nacimiento. En 1841 el ministro de la Gobernación le nombró viceprotector de la Academia de San Fernando, cargo que conservó hasta su fallecimiento. 
Entre los casos de padres e hijos, la información la proporcionan ellos mismos. Por ejemplo, el socio Policarpo María de Tejada Hermoso comunica a la Junta en 1809 que ha fallecido su padre, que fue secretario de la corporación, Policarpo Saenz de Tejada en su villa natal Torrecilla de Cameros ${ }^{104}$. También el afiliado Juan Bautista de Ocio pidió un certificado de los trabajos realizados para la sociedad en el que constasen también los de su padre Juan Antonio Ocio, que había sido socio de mérito artista ${ }^{105}$.

Respecto al parentesco por afinidad, en la documentación revisada solo se ha encontrado el caso de Agustín Idiaquez (miembro desde 1816), cuyo fallecimiento en 1820 lo comunicó su cuñado, el socio José María Celas y Muñoz ${ }^{106}$. Este componente también fue un miembro activo de la institución, ocupándose varias veces de la secretaría en 1811 y de 1816 a 1819, y posteriormente fue contador en 1820.

\section{CONCLUSIONES}

En el estado actual de la investigación se han planteado una serie de cuestiones que se esbozarán a continuación. En primer lugar, se hará referencia a las conclusiones de carácter general, para pasar posteriormente a concretar las que se refieren al análisis particular de los lazos de parentesco.

Nunca se trató de una sociedad con una motivación política, sino una especie de foro de opinión para tratar de trabajar por el desarrollo económico y educativo del país, en general, y del madrileño en particular según las ideas de la llustración. Lo que está claro a primera vista, sin analizar profundamente sus actividades, es que sufrió todos los avatares políticos del periodo. No hay que olvidar que, además de las contribuciones de los socios, que nunca fueron suficientes para el desarrollo de sus fines, se financiaba con aportaciones del Estado, lo que obligaba a tener unas relaciones en concordancia con los gobiernos establecidos. En un periodo tan convulso y variable como fue el reinado de Fernando VII, en cierto modo podía ser peligroso para la supervivencia de la corporación ser independiente del poder político.

En segundo lugar, hay que hacer referencia a la idea que ha llegado hasta la actualidad de la decadencia de la Sociedad Económica Matritense en particular, durante el siglo XIX. En el periodo analizado, por lo menos, la crisis coincide con la restauración del absolutismo más recalcitrante (1823-1833), lo que pone en evidencia que este tipo de instituciones contaron con la oposición de los sectores más reaccionarios del Antiguo Régimen, que aprovecharon primero la existencia de afrancesados y luego de liberales entre sus integrantes para acusarla de ser un

\footnotetext{
104 ARSEM, Libro de Actas de las Juntas de la Sociedad 110/36, Junta de Dirección de 22-7-1809. 105 ARSEM, Libro de Actas de las Juntas de la Sociedad 110/39, Junta de Dirección de 2-12-1815.

106 ARSEM, Legajo 289/6.
} 
foco de revolucionarios y traidores. En la década de los treinta del siglo XIX, con la muerte de Fernando VII y la vuelta de los exiliados liberales a España, se observan momentos de expansión, llegando a contar con gran cantidad de afiliados. Entre las actividades realizadas en esta etapa destaca el patrocinio de la fundación del Ateneo.

Por todo lo anterior, el apoyo del poder político determina el auge o decadencia de la corporación, pues tanto la legislación favorable como la financiación adecuada, son suficientes para su desarrollo, ya que las iniciativas de los partícipes por si solas poco podían hacer. El desarrollo de los fines es producto de tres factores combinados: tolerancia del poder, financiación y asociación. Sin uno de estos pilares, las actividades de la sociedad se resienten.

Como consecuencia del razonamiento anterior, aparece una nueva cuestión, la de la influencia de este tipo de sociedades en el desarrollo económico del país en este periodo. El papel desempeñado por estas entidades no es palpable a primera vista, pues en el reinado de Fernando VII coinciden por un lado, la crisis del Antiguo Régimen, en lo que supone de crisis de instituciones políticas, de propiedad y de estructuras sociales, por otro, la destrucción económica que supuso la Guerra de la independencia y la decadencia comercial por la pérdida de las colonias americanas y, por último, el inicio del fin de la economía y sociedad preindustrial. En este aspecto lo que habria que destacar es el papel de estas instituciones como cauce de introducción de las nuevas ideas económicas, de los adelantos científicos $e$ industriales y su capacidad de difusión hacia el resto de la sociedad.

Otro aspecto a tener en cuenta es el de la evolución del pensamiento. Hay que preguntarse si el origen del Liberalismo español es consecuencia de la evolución de las ideas ilustradas. La trayectoria de dicho pensamiento no confluye directamente en el Liberalismo, como afirma Moreno Alonso en su libro La generación española de $1808^{107}$. La minoría reformista educada en la llustración, toma en 1808 dos caminos diferentes, a consecuencia de la guerra, y no llegará a superar sus diferencias totalmente hasta la década de los treinta del siglo XIX frente al nuevo enemigo común, que se aglutinó en torno al carlismo. En este sentido, en la Sociedad Matritense, al no ser una institución de carácter político, fue más fácil la convivencia de diferentes grupos políticos, sin que se observe el enfrentamiento irreconciliable que se observa en la política española del primer tercio del siglo xIx. Así, los socios de la corporación en todo el periodo pertenecen a toda clase de ideas y grupos políticos y el rechazo hacia ciertos miembros significados políticamente vino impuesto por el poder y no por decisiones surgidas en su seno.

Pasando a otro planteamiento diferente, es necesario profundizar también en el conocimiento de la sociedad madrileña y española de este periodo. El análisis de los socios por su origen, profesión o encuadramiento social revela las actitudes de los diferentes grupos sociales ante el periodo de crisis al que estaban asistiendo y

107 M. MOReno Alonso: La generación española de 1808, Alianza Editorial, Madrid, 1989. 
si era posible la convivencia entre ellos. Por un lado, encontramos la aristocracia de grandes títulos y posesiones, al lado de funcionarios, militares y profesionales 0 artistas. También encontramos a componentes de un clero reformista, al lado de una incipiente burguesía. Todos los integrantes de las minorías o élites ilustradas (entendiendo ilustradas en el sentido de que tenían cierta sensibilidad para el reformismo, las mejoras económicas y sociales y habían accedido a una educación), tienen representantes en la entidad.

En cambio, no deja de llamar la atención que siendo una de las misiones de la matritense el fomento y desarrollo de la agricultura y de la industria, o mejor dicho del artesanado, ya que estamos todavia en un periodo anterior a la revolución industrial, no se encuentren apenas asociados de estos sectores. Se podría alegar que la inmensa mayoría de los obreros y campesinos eran analfabetos y sus condiciones de vida, conviviendo con la pobreza y la miseria, eran suficientes como para autoexcluirse de participar en estas instituciones. La explicación no se revela como suficiente, ya que en la España de inicios del siglo xIx no todos los campesinos viven ínfimamente, pues existían los que eran pequeños propietarios de sus tierras, ni tampoco habia un proletariado homogéneo en las ciudades. Quizá las razones de esta autoexclusión se debe más a cuestiones relacionadas con las diferencias de clase social, es decir, las minorías o elites tienen cierta sensibilidad para los problemas que afectan a la inmensa mayoría del país y quieren intentar solucionar sus problemas pero no mezclarse con ellos. Tendría que ver más con lo que los historiadores del siglo XVIII llaman "despotismo ilustrado" y que en el XIX se convierte en una alianza nobleza-burguesía para una «revolución con orden», evitando a toda costa los excesos que los procesos revolucionarios sin control podían conllevar. Siguiendo este razonamiento las sociedades económicas están más cerca del Liberalismo moderado que del exaltado o del progresismo, como se denominó después.

Un interrogante todavía no aclarado en la investigación hace referencia a algunas afirmaciones vertidas por determinados estudiosos a finales del siglo xIX y principios del siglo $x x$ de que las sociedades económicas estuvieron dominadas por las sociedades secretas que tanto proliferaron a principios del siglo xIX. Aunque algunos autores ya se han encargado de desmentir esta tesis, hasta este momento lo único que se ha podido constatar es que hubo miembros afiliados a sociedades secretas, pero no que la entidad como tal actuase como nido de conspiradores. Estos partícipes se asociaban a la institución como podian pertenecer a otras corporaciones científicas o artísticas, ya que sus campos de interés no sólo eran políti$\cos$, sino que en su vida tuvieron otras inquietudes. Además, sería necesario para establecer la vinculación sociedad económica-sociedad secreta saber si aquéllos que pertenecían a estas últimas ingresaron en la matritense antes o después de afiliarse a las otras. También si todos eran miembros de la misma sociedad secreta o hay tanta variedad como ocurre con las ideas y grupos políticos.

Por último, en cuanto a las conclusiones generales habría que destacar el papel de la mujer en esta institución y, en general, en la sociedad de principios del siglo XIX. A través de esta corporación unas pocas han logrado salir del anonimato al 
que les tiene relegada la historia en general. Por ello es necesario profundizar en los esfuerzos que estuvieron dispuestas a hacer y su contribución a través de las misiones que tuvieron encomendadas, circunscritas a la educación y la beneficencia. El estudio de los informes y memorias realizadas por ellas puede dar la clave de su pensamiento en torno a estas cuestiones, pero también a su propia conciencia respecto a otro tipo de problemas que les afectaban.

A continuación, se esbozarán las conclusiones obtenidas a través del estudio de las relaciones de parentesco que se han observado. Antes de empezar, es necesario insistir en la idea de que al tratarse de solamente de unos cuantos componentes de la corporación en un periodo muy concreto, no pueden ser extrapolables a toda la historia de la matritense. Solo se trata del inicio de una línea de pensamiento que podría llevar a conclusiones, en parte demográficas y sociales más amplias. En todo caso, sin tratar de generalizar, serían las siguientes:

- La decisión de ser socios de la matritense obedece a una iniciativa individual de cada persona, fruto de su interés por el progreso económico del país. Solo en algunos integrantes de la nobleza se observa cierta continuación de padres a hijos en la iniciativa de su incorporación.

- Junto a esta motivación mas o menos declarada, también parecen otras causas menos altruistas, en las que confluyen el prestigio social que proporciona ser miembro de este tipo de instituciones, además de que puede servir para ascensos en determinados empleos y el acercamiento a ciertas esferas de influencia, a las que podría ser difícil acercarse de otra manera. Por eso, es más fácil encontrar nexos de unión de ideas políticas, relaciones profesionales, círculos de amistad e incluso de paisanaje que de consanguinidad.

- Las relaciones de parentesco mas completas se han hallado en la aristocracia, donde coexisten a la vez hermanos, padres, tíos, sobrinos, etc. En el resto de miembros solo han podido encontrarse lazos de consanguinidad entre hermanos. La razón es que si no existe coincidencia en los apellidos es imposible encontrarla, lo cual no quiere decir que no existiera en algunos casos.

- Llama también la atención la excesiva presencia de la aristocracia en la Junta de Damas, producto de que solo a partir de cierto nivel económico y social les era posible a las mujeres pertenecer a este tipo de instituciones. La falta de tiempo por la dedicación exclusiva de la mujer a la familia y la educación actuaban como freno para su incorporación.

- Este aspecto se reafirma con las vinculaciones matrimoniales entre socios y socias encontradas, ya que son frecuentes entre miembros de la nobleza y casi inexistentes entre el resto.

- Otra idea a destacar es la excesiva endogamia de la aristocracia española de finales del siglo XVIII y principios del XIX. Esta conclusión que está presente en los diferentes estudios que, en torno a la nobleza han hecho diversos histo- 
riadores que se han ocupado del tema, se ve confirmada por la repetición de apellidos y relaciones familiares en esta pequeña investigación se han podido constatar. Además, lleva a conclusiones más amplias como son las de las causas de la decadencia de la aristocracia en el siglo XIX, no solo en cuanto a que su falta de adaptación a los nuevos tiempos provocó la pérdida de su influencia política y su ruina económica, sino que la concentración de títulos y las políticas matrimoniales no condujeron a los resultados deseados de conservación de privilegios e influencia.

- Por último, no deja de llamar la atención lo que se intuye como una tradición ilustrada. Los grandes ministros del siglo XVIII, como fueron el marqués de la Ensenada, Floridablanca, Campomanes, Cabarrús o Aranda, tienen su continuación en sus descendientes, ya que todos ellos tienen familiares tanto masculinos como femeninos que estuvieron afiliados en algún momento a la entidad. 